\title{
Improving Energy Efficiency in Buildings Using an Interactive Mathematical Programming Approach
}

\author{
Christina Diakaki ${ }^{1,2, *(D)}$ and Evangelos Grigoroudis ${ }^{1}$ (D) \\ 1 School of Production Engineering and Management, Technical University of Crete, 73100 Chania, Greece; \\ vangelis@ergasya.tuc.gr \\ 2 School of Social Sciences, Hellenic Open University, 26335 Patra, Greece \\ * Correspondence: cdiakaki@isc.tuc.gr
}

Citation: Diakaki, C.; Grigoroudis, E. Improving Energy Efficiency in Buildings Using an Interactive Mathematical Programming Approach. Sustainability 2021, 13, 4436. https://doi.org/10.3390/ su13084436

Academic Editor:

Georgios Tsantopoulos

Received: 13 March 2021

Accepted: 14 April 2021

Published: 15 April 2021

Publisher's Note: MDPI stays neutral with regard to jurisdictional claims in published maps and institutional affiliations.

Copyright: (C) 2021 by the authors. Licensee MDPI, Basel, Switzerland. This article is an open access article distributed under the terms and conditions of the Creative Commons Attribution (CC BY) license (https:/ / creativecommons.org/licenses/by/ $4.0 /)$.

\begin{abstract}
Improving energy efficiency in buildings is a major priority and challenge worldwide. The employed measures vary in nature, and the decision analyst, who is typically the architect, the engineer, or the building expert that has undertaken the task to suggest energy efficient solutions, faces a complex decision problem comprising numerous decision variables and multiple, usually competitive objectives. The solution of such multi-objective problems typically involves some sort of objectives aggregation, which reflects the preferences of the involved final decision maker that is the building's user, occupant, and/or owner. The preferences elicitation, however, is a difficult task, and this paper aims to provide an interactive framework that will allow their consideration in a relatively easy manner. More specifically, a mathematical programming approach is proposed herein, which allows the elicitation and incorporation of the decision maker's preferences in the decision model via the assessment of his/her utility function with the assistance of the multicriteria decision aid method UTASTAR. To study the feasibility and efficiency of the proposed approach, the case of a simple building is examined as an application example. The study results suggest that the proposed approach is capable of helping the decision analyst to suggest energy measures that satisfy, as much as possible, the decision maker's preferences, without having to precisely prescribe them beforehand.
\end{abstract}

Keywords: buildings; energy efficiency; energy efficiency improvement; multi-objective optimization; preference disaggregation; preference elicitation; value system; utility function

\section{Introduction}

Despite the long-lasting research and development in the particular field, the problem of improving energy efficiency in buildings still remains under investigation, according to recent reviews [1,2], due to its inherent complexity. The complexity of the problem stems from the involvement of several, typically competitive objectives (e.g., cost versus energy consumption) and the availability of numerous alternative measures (e.g., addition of insulation, change of color, use of cool coatings and renewables, etc.) [3], based on which, a final choice has to be made.

In practice, the specific measures to be adopted are typically suggested by the architect, the engineer, or the building expert, who undertakes the task to study the problem, thus playing the role of the decision analyst (DA). However, for any suggestions to be accepted by the final decision maker (DM), who may be the building's user, occupant, and/or owner, they have to satisfy his/her specific requirements and preferences. This further increases the complexity of the problem, and calls for solution approaches that allow the realistic comparative evaluation of all the available alternatives [4]. Such an approach has been proposed by Diakaki et al. [5], who developed a relevant multi-objective decision model based on the principles of mathematical programming.

The aforementioned model considers as objectives to minimize the primary energy consumption of a building and the released $\mathrm{CO}_{2}$ emissions during operation, as well as the initial investment cost. The particular formulation lends itself for solution via mathematical 
optimization techniques [5], as well as evolutionary methods like genetic algorithms [6], should the problem complexity become such that a solution via analytic techniques is no longer feasible. Despite the reduced precision compared to the simulation models typically employed for the evaluation of alternative measures [2], the mathematical programmingbased approach has been proved to allow for the realistic comparative evaluation of all the available, alternative measures [7], it has thus been adopted by several researchers in the field (see, e.g., [8-13]).

Irrespective of the particular technique that one may employ for the solution of a multi-objective mathematical programming problem, to reach a single, final solution, which will be satisfactory, thus acceptable by the corresponding DM, weights need to be assigned to the different objectives $[2,14]$. These weights reflect the relevant importance of each considered objective to the $\mathrm{DM}$, and/or the trade-off that exists among them, due to their competitive nature. The determination of such weights is a difficult task, as it is very unlikely for a DM to be able to explicitly state his/her preferences and satisfaction levels for each and every considered objective. Thus, rather than trying to determine the criteria weights [14], the implicit elicitation and learning of the preferences and value system of the $\mathrm{DM}$, and their incorporation and use in the decision making process, seems more convenient. The development of such an approach for the multi-objective decision problem of improving energy efficiency in buildings is the purpose of the work presented herein.

Specifically, it is the aim of this paper to present an approach, whereby the DA will manage to reach a single, final solution of maximum utility to the DM, as an outcome of an interactive process of individual inter-alternative preference modelling. To this end, the main principles and rationale of a two-phase, iterative procedure proposed by Siskos and Despotis [15] for similar decision problem settings have been adopted. The procedure starts with identifying an initial compromise solution for the energy efficiency improvement problem established in Diakaki et al. [5] (first phase), and then runs iteratively (second phase) as many times as necessary to extract the DM's aspiration levels for each objective, and estimate a respective utility function, which is used in order to reach a single, final solution, which is as close as possible to the DM's actual preferences and value system. Throughout the iterative procedure, interaction is offered at two levels: (i) interactive modification of the DM's satisfaction levels on the different pursued objectives; and (ii) interactive assessment of the DM's utility function via the development and use of the UTASTAR multicriteria decision aid model [16]. UTASTAR is a preference disaggregation approach, which aims at inferring the value or utility function(s) of a DM, given his/her expressed preferences over a reference set of alternatives.

Through the aforementioned interactive procedure, the proposed approach allows the DA to (a) develop the DM's overall utility function for the considered problem; (b) solve the problem by optimizing the developed utility function, rather than aggregating the individual objective functions of the considered problem via potentially arbitrary weights, like in the original multi-objective problem formulation in [5]; and (c) reach a single, final solution of maximum utility to the DM.

To study the feasibility and efficiency of the proposed approach, the case of a simple building is examined as an application example. The study results suggest that the proposed approach is capable of helping the DA to select and suggest energy measures that satisfy, as much as possible, the DM's spectrum of desires, without having to precisely prescribe them beforehand.

The rest of the paper is structured in three more sections. Section 2 introduces the proposed approach, while Section 3 presents the application example. Section 4 discusses the results and findings, and Section 5, finally, summarizes the conclusions of the study and highlights future research directions. 


\section{Materials and Methods}

\subsection{Overview}

The approach proposed herein builds upon the mixed-integer, non-linear, multiobjective optimization problem developed by Diakaki et al. [5], which may be generally defined as follows:

$$
\begin{gathered}
\min \left[g_{1}(\mathbf{x}), g_{2}(\mathbf{x}), \ldots, g_{n}(\mathbf{x})\right] \\
\text { subject to } \mathbf{x} \in X,
\end{gathered}
$$

where $\mathbf{x}=\left(x_{1}, x_{2}, \ldots, x_{m}\right)$ is the vector of $m$ binary or continuous decision variables reflecting alternative choices (e.g., doors and windows types that can be used in the building, structure of multi-layer components such as walls, ceilings, and floors, materials to be used for their construction, and systems that can be used for heating, cooling and hot water supply), $X \subseteq R^{m}$ is the feasible region or decision space of the problem under study, which is implicitly dictated by a set of constraints concerning the decision variables and their intermediary relations; and $g_{1}(\mathbf{x}), g_{2}(\mathbf{x}), \ldots g_{n}(\mathbf{x})$ are the values of $n$ considered objectives. In the problem defined in [5], $n=3$, as the considered objectives are the total annual primary energy consumption (MJ/year), the $\mathrm{CO}_{2}$ emissions $\left(\mathrm{kg} \mathrm{CO}_{2}\right.$ /year) released to the environment by the operation of the heating, cooling, and/or hot water supply systems, and the investment cost for the construction or retrofit of the building envelope and the acquisition and installation of the aforementioned systems, respectively.

The decision model (1) is used herein in the following two-phase procedure:

1. In the first phase, each individual objective of (1) is first minimized and then maximized over the set of the feasible solutions, thus providing lower and upper bounds for the objectives. Given that $g_{i}(\mathbf{x})$ are minimized in (1), the lower bounds represent the ideal values of the objectives, and remain the same throughout the whole process, while the upper bounds represent the anti-ideal ones, and are refined during the second phase of the procedure. In addition, an initial efficient solution, i.e., a solution, which is not dominated by any other acceptable solution in the decision space is estimated that is closest to the ideal one with respect to the weighted Tchebycheff norm [15].

2. In the second phase, an iterative process is followed, which comprises three successive steps. The first step can be viewed as a learning process of the trade-offs among the objectives for the DM. Through questions and answers, this step refines the upper bounds, thus gradually reducing the feasible region of the decision problem. The second step can be viewed as a learning process of the DM's preferences. During this step, the DM is asked to rank, according to his/her preferences, a reference set of fictitious non-dominated decision profiles. This subjective ranking is then used by a UTASTAR model to generate the DM's utility function $u$, over the intervals created by the lower and upper limits of the objectives' values, and use them in transforming the decision problem (1) in the following:

$$
\begin{gathered}
\max u[\mathbf{g}(\mathbf{x})] \\
\text { subject to } \mathbf{x} \in X,
\end{gathered}
$$

where, $\mathbf{g}(\mathbf{x})=\left(g_{1}(\mathbf{x}), g_{2}(\mathbf{x}), \ldots, g_{n}(\mathbf{x})\right)$ is the vector of the values of the objectives of the initial Problem (1). The decision Problem (2) is solved in the third step of the process, the solution is presented to the DM, and the iterations restart until a solution is reached that will be sufficiently satisfactory for the DM, so that he/she will not wish to further improve it.

Figure 1 presents the flowchart of the aforementioned procedure, while the following subsection provides the details of its different phases. 


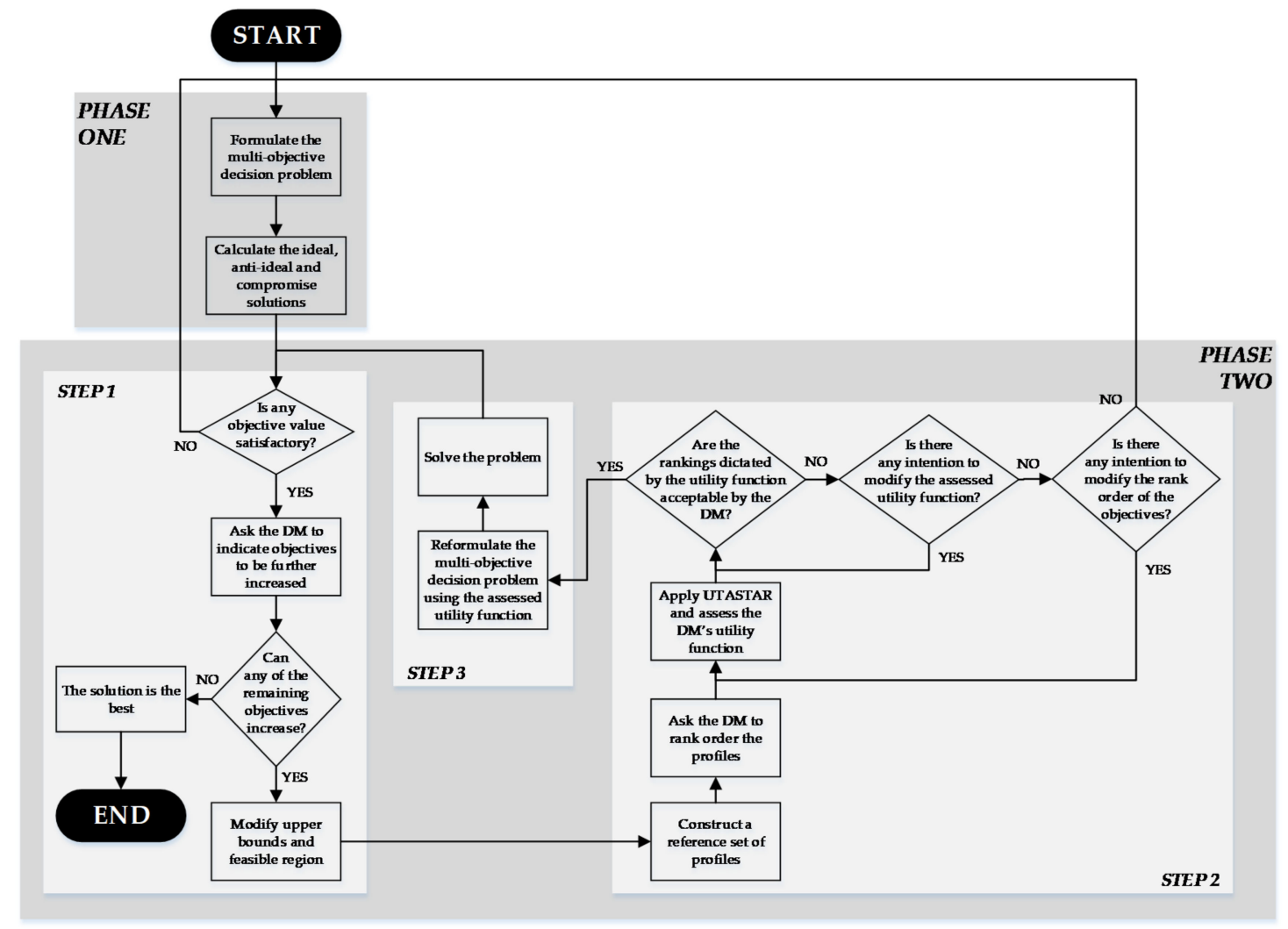

Figure 1. The flowchart of the interactive multi-objective mathematical programming approach.

\subsection{The Interactive Mathematical Programming Approach}

\subsubsection{Phase One}

As mentioned earlier, within the first phase of the proposed interactive mathematical programming approach, the individual objectives of decision Problem (1) are minimized and maximized to establish the initial lower and upper bounds of the objectives. More specifically, the lower bound $l_{i}$, which is the ideal solution for each objective $i$, with $i=1,2, \ldots, n$, is calculated as follows:

$$
\begin{gathered}
l_{i}=\min \left[g_{i}(\mathbf{x})\right] \\
\text { subject to } \mathbf{x} \in X,
\end{gathered}
$$

while for the upper bound $h_{i}$, which is the anti-ideal solution, the following problem is solved:

$$
\begin{gathered}
h_{i}=\max \left[g_{i}(\mathbf{x})\right] \\
\text { subject to } \mathbf{x} \in X .
\end{gathered}
$$

Then, an initial compromise solution is obtained via the solution of the following problem:

$$
\begin{gathered}
\min z \\
\text { subject to } \mathbf{x} \in X \\
z>m_{i}\left(g_{i}(\mathbf{x})-l_{i}\right), i=1,2, \ldots, n \\
z>0
\end{gathered}
$$

where

$$
m_{i}=d_{i} / \sum_{i} d_{i}, i=1,2, \ldots, n,
$$

and

$$
d_{i}=\left(h_{i}-l_{i}\right) / h_{i}, i=1,2, \ldots, n
$$


The solution of Problem (5) is the closest one to the ideal values of the objectives calculated via (3) in the sense of the weighted Tchebycheff norm.

\subsubsection{Phase Two}

The second phase of the proposed interactive mathematical programming approach is the iterative one, so let $q$ be the number of iteration. Let also $X^{q}$ be the feasible region, $h_{i}^{q}$ the upper bound of objective $i$, and $\mathbf{g}^{q}$ the vector of the optimal values of the objectives reached in iteration $q$.

When entering for the first time in phase two, for the upper bounds and the objectives values, the following hold:

- The upper bound values $h_{i}^{0}$ are equal to the solutions of the corresponding problems (4), obtained in phase one;

- The optimal values of the objectives $\mathbf{g}^{0}$ are equal to the values obtained via the solution of the multi-objective Problem (5) in phase one.

In addition, $X^{0}=X$ holds.

Given the above initial values, as well as the lower bounds $l_{i}$, i.e., the ideal solutions of the objectives, the three steps described below are successively executed.

\section{Step 1}

At the first step of phase two, interaction takes place in order to learn the trade-offs among the objectives for the DM. More specifically, the DM is asked to express his/her satisfaction with respect to the values of the objectives that have been reached so far, i.e., for the values in $\mathbf{g}^{q-1}$.

If the DM does not find any objective value satisfactory, the multi-objective decision problem has no satisfactory solution. In such case, the problem should be reviewed and revised, and the procedure should restart from phase one. However, if some values in $\mathbf{g}^{q-1}$ are satisfactory, the DM is asked to suggest the objectives, which he/she insists to further decrease, and the whole set of objectives $G$ is split in the following two complementary sets:

- $G_{D}$ : the subset of $G$, which comprises the objectives that the DM insists to decrease;

- $\bar{G}_{D}$ : the complement of $G_{D}$ in $G$.

Given the split of $G$ in the two subsets, the DM is asked again to suggest, if there are any objectives in $\bar{G}_{D}$, which could be increased to make room for the desired further decrease of the objectives in $G_{D}$. If the response to this question is no, there is no room for further improvement, the procedure stops, and the solution reached so far is the best compromise solution to the examined problem. If, however, the response of the DM is yes, the upper bounds of the objectives are updated as follows:

$$
h_{i}^{q}=\left\{\begin{array}{l}
g_{i}^{q-1} \text { if } g_{i} \in G_{D} \\
h_{i}^{q-1} \text { if } g_{i} \in \bar{G}_{D}
\end{array}\right.
$$

For each $g_{j} \in G_{D}$, the following problem is solved:

$$
\begin{aligned}
& \min g_{j}(\mathbf{x}) \\
& \text { subject to } \mathbf{x} \in X \\
& \qquad g_{i}(\mathbf{x}) \leq h_{i}^{q} i=1,2, \ldots, n \text { and } i \neq j,
\end{aligned}
$$

and the feasible region is finally reduced as shown below:

$$
X^{q}=X^{q-1} \cap\left\{\mathbf{x} \in R^{m} / g_{i}(x) \leq h_{i}^{q}, i=1,2, \ldots, n\right\} .
$$


Step 2

The second step of phase two is also a learning process aiming at the DM's preferences elicitation. To this end, for an arbitrary chosen integer $s, s+1$ reference alternative profiles $a_{k}$, with $k=0,1, \ldots, s$, are generated. Each profile comprises a coordinate $a_{i k}$ for each objective $i$, which is calculated as follows:

$$
a_{i k}=l_{i}+(k / s)\left(h_{i}^{q}-l_{i}\right)
$$

Apparently, any other number of alternative profiles, as well as profiles generation procedure, can be adopted, as long as the generated profiles are representative of the trade-off among the objectives, and do not dominate each other. As their purpose is not to be offered to the DM as possible problem solutions, the generated profiles do not need to be efficient or feasible. They are just presented to the DM, who is asked to rank order them. The ranked set of alternative profiles is then used in the UTASTAR method [16] to assess the DM's utility function $u[\mathbf{g}(\mathbf{x})]$, as described in Appendix A.

Step 3

The utility function assessed in Step 2 is maximized in this last step over the feasible region. In other words, the Problem (2) is modified as follows, to take into account the reduction of the decision space according to (10):

$$
\begin{aligned}
& \max u[\mathbf{g}(\mathbf{x})] \\
& \text { subject to } \mathbf{x} \in X^{q},
\end{aligned}
$$

and then solved.

The solution of Problem (12) marks the end of the current iteration, and the procedure restarts from step 1 with the new solution, feasible region, and upper objective bounds.

\section{Application Example}

\subsection{Overview of the Decision Problem}

To assess the feasibility and efficiency of the proposed approach in suggesting measures that satisfy the competitive objectives of the energy efficiency improvement problem in a way that is compatible with the preferences and value system of the DM, the case of a simple building is studied. The building, taken from the study of Diakaki et al. [5], assumes an envelope, which comprises a floor and ceiling area of $100 \mathrm{~m}^{2}, 2$ walls of area $24 \mathrm{~m}^{2}, 2$ walls of area $30 \mathrm{~m}^{2}$, and a door and window area both of $6 \mathrm{~m}^{2}$.

The decisions regarding the considered building concern appropriate choices for:

- The type of the building's door and window among the alternatives of Tables 1 and 2, respectively;

- the structure of the building's walls, ceiling, and floor among the alternatives of Tables 3-5, respectively;

- the addition or not, in the building's walls, ceiling, and floor, of an insulation layer of maximum permissible thickness $0.10 \mathrm{~m}$ and material chosen among the alternatives of Table 6;

- $\quad$ the space heating system among the alternatives of Tables 7-9;

- $\quad$ the space cooling system among the alternatives of Table 8;

- the hot water supply system(s) among the alternatives of Tables 9 and 10; and

- the addition or not of a solar collector system among the alternatives of Table 11. 
Table 1. Alternative door types.

\begin{tabular}{ccc}
\hline Type & $\begin{array}{c}\text { Thermal Transmittance } \\
\left(\mathbf{W} / \mathbf{m}^{\mathbf{2}}{ }^{\circ} \mathbf{C}\right)\end{array}$ & $\begin{array}{c}\text { Cost } \\
\left(\boldsymbol{\epsilon} / \mathbf{m}^{\mathbf{2}}\right)\end{array}$ \\
\hline 1. Hollow-core flush door & 2.7 & 800 \\
2. Solid-core flush door with single glazing (17\% glass) & 2.1 & 1000 \\
\hline
\end{tabular}

Table 2. Alternative window types.

\begin{tabular}{ccccc}
\hline Type & Subtype & $\begin{array}{c}\text { Thermal } \\
\text { Transmittance } \\
\left(\mathbf{W} / \mathbf{m}^{\mathbf{2}}{ }^{\circ} \mathbf{C}\right)\end{array}$ & $\begin{array}{c}\text { Effective Total Solar } \\
\text { Energy Transmittance } \\
\mathbf{( \% )}\end{array}$ & $\begin{array}{c}\text { Cost } \\
\left(\boldsymbol{(} / \mathbf{m}^{\mathbf{2}}\right)\end{array}$ \\
\hline 1. Single glazing & 1. Typical glazing & 5.0 & 80 & 40 \\
2. Double glazing & 1. 4-20-4, uncoated, air filled & 2.6 & 72 & 55 \\
& 2. 4-12-4, coated, argon filled & 1.6 & 76 & 65 \\
\hline
\end{tabular}

Table 3. Alternative wall structures.

\begin{tabular}{|c|c|c|c|c|c|}
\hline Structure & Layer & Material & $\begin{array}{l}\text { Thickness } \\
\text { (m) }\end{array}$ & $\begin{array}{l}\text { Thermal Conductivity } \\
\left(\mathrm{W} / \mathrm{m}^{\circ} \mathrm{C}\right)\end{array}$ & $\begin{array}{l}\text { Cost } \\
\left(€ / \mathrm{m}^{3}\right)\end{array}$ \\
\hline \multirow[t]{3}{*}{1} & 1 & Plaster & 0.025 & 0.87 & 10 \\
\hline & 2 & Brick (complex) & 0.150 & 0.72 & 23 \\
\hline & 3 & Plaster & 0.025 & 0.87 & 10 \\
\hline \multirow[t]{4}{*}{2} & 1 & Plaster & 0.025 & 0.87 & 10 \\
\hline & 2 & Brick (complex) & 0.060 & 0.72 & 6.2 \\
\hline & 3 & Brick (complex) & 0.060 & 0.72 & 6.2 \\
\hline & 4 & Plaster & 0.025 & 0.87 & 10 \\
\hline
\end{tabular}

Table 4. Alternative ceiling structures.

\begin{tabular}{|c|c|c|c|c|c|}
\hline Structure & Layer & Material & $\begin{array}{l}\text { Thickness } \\
\text { (m) }\end{array}$ & $\begin{array}{l}\text { Thermal Conductivity } \\
\left(\mathrm{W} / \mathrm{m}^{\circ} \mathrm{C}\right)\end{array}$ & $\begin{array}{c}\text { Cost } \\
\left(€ / \mathrm{m}^{3}\right)\end{array}$ \\
\hline \multirow[t]{2}{*}{1} & 1 & Tiles & 0.02 & 1.00 & 55 \\
\hline & 2 & Concrete & 0.15 & 0.72 & 55 \\
\hline \multirow[t]{2}{*}{2} & 1 & Tiles & 0.02 & 1.00 & 55 \\
\hline & 2 & Wood & 0.03 & 0.17 & 70 \\
\hline
\end{tabular}

Table 5. Alternative floor structures.

\begin{tabular}{|c|c|c|c|c|c|}
\hline Structure & Layer & Material & $\begin{array}{l}\text { Thickness } \\
\text { (m) }\end{array}$ & $\begin{array}{l}\text { Thermal Conductivity } \\
\left(\mathrm{W} / \mathrm{m}^{\circ} \mathrm{C}\right)\end{array}$ & $\begin{array}{l}\text { Cost } \\
\left(€ / \mathrm{m}^{3}\right)\end{array}$ \\
\hline \multirow[t]{2}{*}{1} & 1 & Tiles & 0.01 & 1.00 & 55 \\
\hline & 2 & Concrete & 0.15 & 0.72 & 55 \\
\hline \multirow[t]{2}{*}{2} & 1 & Wood & 0.02 & 0.17 & 85 \\
\hline & 2 & Concrete & 0.15 & 0.72 & 55 \\
\hline
\end{tabular}

Table 6. Alternative insulation materials.

\begin{tabular}{ccc}
\hline Material & $\begin{array}{c}\text { Thermal Conductivity } \\
\left(\mathbf{W} / \mathbf{m}^{\circ} \mathbf{C}\right)\end{array}$ & $\begin{array}{c}\text { Cost } \\
\left(\boldsymbol{(} / \mathbf{m}^{3}\right)\end{array}$ \\
\hline 1. Polystyrene & 0.036 & 200 \\
2. Mineral fiber & 0.042 & 180 \\
3. Plastic fiber & 0.020 & 300 \\
\hline
\end{tabular}


Table 7. Alternative heating-only systems.

\begin{tabular}{|c|c|c|c|}
\hline Category & Type & $\begin{array}{c}\text { Generation Efficiency } \\
(\%)\end{array}$ & $\begin{array}{c}\text { Cost } \\
(€)\end{array}$ \\
\hline \multicolumn{4}{|l|}{ Electrical systems } \\
\hline \multirow{2}{*}{ 1. Resistance-based } & 1. Dry core storage boiler type 1 & 100 & 5000 \\
\hline & 2. Dry core storage boiler type 2 & 85 & 4200 \\
\hline \multicolumn{4}{|l|}{ Non-electrical systems } \\
\hline \multirow[t]{2}{*}{ 1. Oil-based } & 1. Condensing & 83 & 5300 \\
\hline & 2. Standard oil boiler & 62 & 4700 \\
\hline \multirow[t]{2}{*}{ 2. Natural-gas based } & 1. Condensing & 85 & 5800 \\
\hline & 2. Floor mounted boiler & 55 & 4500 \\
\hline
\end{tabular}

Table 8. Alternative heating-cooling systems.

\begin{tabular}{|c|c|c|c|}
\hline Category & Type & $\begin{array}{c}\text { Generation Efficiency } \\
(\%)\end{array}$ & $\begin{array}{c}\text { Cost } \\
(€)\end{array}$ \\
\hline \multirow[t]{3}{*}{ 1. Water cooled electric } & 1. $<12,000 \mathrm{BTU}$ & 200 & 500 \\
\hline & 2. $<18,000 \mathrm{BTU}$ & 230 & 800 \\
\hline & 3. $<24,000 \mathrm{BTU}$ & 250 & 1200 \\
\hline
\end{tabular}

Table 9. Alternative heating-hot water supply systems.

\begin{tabular}{|c|c|c|c|}
\hline Category & Type & $\begin{array}{c}\text { Generation Efficiency } \\
(\%)\end{array}$ & $\begin{array}{c}\text { Cost } \\
(€)\end{array}$ \\
\hline \multicolumn{4}{|l|}{ Electrical systems } \\
\hline \multirow{2}{*}{ 1. Resistance-based } & 1. Electric CPSU & 100 & 7200 \\
\hline & 2. Water storage boiler & 85 & 5800 \\
\hline \multicolumn{4}{|l|}{ Non-electrical systems } \\
\hline \multirow[t]{2}{*}{ 1. Oil-based } & 1. Condensing combi & 81 & 6200 \\
\hline & 2. Combi & 70 & 5800 \\
\hline \multirow[t]{2}{*}{ 2. Natural-gas based } & 1. Condensing combi & 84 & 7200 \\
\hline & 2. Combi & 65 & 5700 \\
\hline
\end{tabular}

Table 10. Alternative hot water supply-only systems.

\begin{tabular}{|c|c|c|c|}
\hline Category & Type & $\begin{array}{c}\text { Generation Efficiency } \\
(\%)\end{array}$ & $\begin{array}{c}\text { Cost } \\
(€)\end{array}$ \\
\hline \multicolumn{4}{|l|}{ Electrical systems } \\
\hline \multirow[t]{2}{*}{ 1. Resistance-based } & 1. Electric immersion & 100 & 1200 \\
\hline & 2. Electric instantaneous at point of use & 85 & 1000 \\
\hline \multicolumn{4}{|l|}{ Non-electrical systems } \\
\hline \multirow[t]{2}{*}{ 1. Oil-based } & 1. Oil boiler/circulator & 80 & 1000 \\
\hline & 2. Oil single burner & 60 & 800 \\
\hline \multirow[t]{2}{*}{ 2. Natural-gas based } & $\begin{array}{l}\text { 1. Circulator built into a gas warm air } \\
\text { system type } 1\end{array}$ & 73 & 850 \\
\hline & $\begin{array}{l}\text { 2. Circulator built into a gas warm air } \\
\text { system type } 2\end{array}$ & 60 & 650 \\
\hline
\end{tabular}

Table 11. Alternative solar collector systems.

\begin{tabular}{|c|c|c|c|}
\hline Category & Type & $\begin{array}{c}\text { Generation Efficiency } \\
(\%)\end{array}$ & $\begin{array}{c}\text { Cost } \\
(€)\end{array}$ \\
\hline \multirow[t]{2}{*}{ 1. Flat collector } & 1. Type 1 & 90 & 900 \\
\hline & 2. Type 2 & 80 & 600 \\
\hline \multirow{2}{*}{ 2. Vacuum hear pipe CPC collector } & 1. Type 1 & 72 & 780 \\
\hline & 2. Type 2 & 67 & 500 \\
\hline
\end{tabular}


The values of the thermal and solar transmittance, and the thermal conductivity of construction materials and components in Tables 1-6 have been taken from the ASHRAE database [17], while the cost values in all the aforementioned tables were obtained through a short, unofficial market survey that took place for the needs of the study described in [5].

The application of the multi-objective decision modelling approach to the particular decision problem leads to a mathematical model of the form (1), which includes 18 continuous and 57 binary variables. The model, which is summarized in Appendix B, aims at determining measures that minimize the following three objectives:

- The primary energy consumption $g_{1}(\mathbf{x})$;

- the release of $\mathrm{CO}_{2}$ emissions $g_{2}(\mathbf{x})$; and

- the initial investment cost $g_{3}(\mathbf{x})$.

These objectives are competitive, since, typically, the cost-efficient solutions are less environmentally friendly and vice versa. Thus, the search for a globally optimal solution is infeasible, and the DA has to search for a feasible solution, which will comply as much as possible with the DM's preferences and value system. To assist the DA in this search, the multi-phase iterative procedure described in Section 2 is applied.

\subsection{Application of the Interactive Mathematical Programming Approach \\ 3.2.1. Phase One}

In the first phase of the proposed approach, the individual objectives of the examined decision problem are minimized and maximized, according to (3) and (4), respectively, in order to establish the ideal and anti-ideal solutions of the problem. In addition, an initial compromise solution is identified via the solution of Problem (5).

Table 12 summarizes the outcomes of this phase. The outcomes clearly demonstrate that the choices made depend on the pursued objective(s). For example, when the objective is solely to minimize the primary energy consumption, the most energy efficient choices are made in contrast to the choices made when aiming solely at the reduction of the initial investment cost. In this latter case, the cheapest choices are made, which are the worst from the energy efficiency perspective. These two objectives are clearly competitive to each other, but also to the emissions objective. The release of $\mathrm{CO}_{2}$ emissions does not depend solely on the generation efficiency of the heating, cooling, and hot water supply systems, but also on the utilized fuel. Thus, some energy efficient choices are no longer efficient when emissions come into the picture.

Table 13 summarizes and highlights the basic information about the problem at hand, which has been generated by the proposed approach in phase one. More specifically, the table comprises the ideal and anti-ideal objective values, the initial upper bound for each objective, the initial compromise solution, as well as the rate of closeness of the objectives to their ideal values, being calculated as follows:

$$
\text { Rate of closeness to the ideal solution }=100 \frac{g_{i}^{q}-l_{i}}{h_{i}-l_{i}}
$$

with $q$ the number of iteration; for phase one, $q=0$ holds. Apparently, the lower the value of the rate, the better.

Table 13 makes clear that the initial compromise solution comprises choices that lead the objectives of primary energy consumption and release of $\mathrm{CO}_{2}$ emissions very close to their ideal solutions (rates of closeness are $0.85 \%$ and $1.59 \%$, respectively). The initial investment cost, on the other hand, is not similarly close to its ideal value (rate of closeness is $38.80 \%$ ), and this may cause dissatisfaction to the DM. For this reason, the second phase of the proposed approach is activated, to examine the satisfaction level of the DM and refine, if necessary, the problem solution. 
Table 12. Summary of phase one outcomes.

\begin{tabular}{|c|c|c|c|c|c|c|c|}
\hline \multirow[t]{3}{*}{ Decisions and Criteria } & \multicolumn{7}{|c|}{ Type of Solution } \\
\hline & \multicolumn{3}{|c|}{ Minimize } & \multicolumn{3}{|c|}{ Maximize } & \multirow[t]{2}{*}{ Compromise } \\
\hline & $g_{1}(\mathbf{x})$ & $g_{2}(\mathbf{x})$ & $g_{3}(\mathbf{x})$ & $g_{1}(\mathbf{x})$ & $g_{2}(\mathbf{x})$ & $g_{3}(\mathbf{x})$ & \\
\hline Door type & 2 & 2 & 1 & 1 & 1 & 2 & 1 \\
\hline Window type/subtype & $2 / 2$ & $2 / 2$ & $1 / 1$ & $1 / 1$ & $1 / 1$ & $2 / 2$ & $2 / 2$ \\
\hline Wall structure & 1 & 1 & 2 & 2 & 2 & 1 & 2 \\
\hline Wall insulation thickness (m) & 0.10 & 0.10 & 0.00 & 0.00 & 0.00 & 0.10 & 0.07 \\
\hline Wall insulation material & 3 & 3 & - & - & - & 3 & 3 \\
\hline Ceiling structure & 1 & 1 & 2 & 2 & 2 & 1 & 2 \\
\hline Ceiling insulation thickness (m) & 0.10 & 0.10 & 0.00 & 0.00 & 0.00 & 0.10 & 0.07 \\
\hline Ceiling insulation material & 3 & 3 & - & - & - & 3 & 3 \\
\hline Floor structure & 2 & 2 & 1 & 1 & 1 & 2 & 1 \\
\hline Floor insulation thickness (m) & 0.10 & 0.10 & 0.00 & 0.00 & 0.00 & 0.10 & 0.07 \\
\hline Floor insulation material & 3 & 3 & - & - & - & 3 & 3 \\
\hline Heating system type & $\mathrm{EHC}$ & $\mathrm{NEH}$ & $\mathrm{EHC}$ & EHW & EHW & EHW & $\mathrm{EHC}$ \\
\hline Heating system category/type & $1 / 3$ & $2 / 1$ & $1 / 1$ & $1 / 2$ & $1 / 2$ & $1 / 1$ & $1 / 3$ \\
\hline Cooling system type & - & $\mathrm{EC}$ & - & $\mathrm{EC}$ & $\mathrm{EC}$ & $\mathrm{EC}$ & - \\
\hline Cooling system category/type & - & $1 / 3$ & - & $1 / 1$ & $1 / 1$ & $1 / 3$ & - \\
\hline Hot water supply system type & NEW & NEW & NEW & - & - & - & NEW \\
\hline $\begin{array}{c}\text { Hot water supply system } \\
\text { category/type }\end{array}$ & $1 / 1$ & $2 / 1$ & $2 / 2$ & - & $1 / 2$ & - & $2 / 2$ \\
\hline Solar collector category/type & $1 / 1$ & $1 / 1$ & - & - & - & $1 / 1$ & $2 / 2$ \\
\hline $\begin{array}{c}g_{1}: \text { Primary energy } \\
\text { consumption (MJ/year) }\end{array}$ & 13,593 & 13,970 & 321,276 & 722,123 & 722,123 & 32,475 & 19,582 \\
\hline $\begin{array}{l}g_{2}: \text { Release of } \mathrm{CO}_{2} \text { emissions } \\
\left(\mathrm{kg} \mathrm{CO}_{2} / \text { year }\right)\end{array}$ & 1400 & 810 & 32,758 & 74,559 & 74,559 & 3353 & 1986 \\
\hline$g_{3}:$ Initial investment cost $(€)$ & 21,987 & 27,637 & 7524 & 12,674 & 12,674 & 28,187 & 15,540 \\
\hline
\end{tabular}

EHC: electrical system that will be used for both heating and cooling (see Table 8); EHW: electrical system that will be used for both heating and hot water supply (see Table 9); EC: electrical system that will be used only for cooling (see Table 8); NEH: electrical system that will be used only for heating (see Table 7); NEW: non-electrical system that will be used only for hot water supply (see Table 10).

Table 13. Basic information generated in phase one (iteration $q=0$ ).

\begin{tabular}{|c|c|c|c|}
\hline Information & $\begin{array}{l}\text { Primary Energy } \\
\text { Consumption } \\
\text { (MJ/Year) } \\
i=1\end{array}$ & $\begin{array}{c}\text { Release of } \mathrm{CO}_{2} \text { Emissions } \\
(\mathrm{kg} \mathrm{CO} / \text { Year } \\
i=2\end{array}$ & $\begin{array}{c}\text { Initial Investment Cost } \\
(€) \\
i=3\end{array}$ \\
\hline Ideal solution (lower bound) $l_{i}$ & 13,593 & 810 & 7524 \\
\hline Initial compromise solution $g_{i}^{0}$ & 19,582 & 1986 & 15,540 \\
\hline Anti-ideal solution $h_{i}$ & 722,123 & 74,559 & 28,187 \\
\hline Initial upper bound $h_{i}^{0}$ & 722,123 & 74,559 & 28,187 \\
\hline Rate of closeness to the ideal solution & $0.85 \%$ & $1.59 \%$ & $38.80 \%$ \\
\hline
\end{tabular}

\subsubsection{Phase Two-Iteration 1-Step 1}

Entering in phase two, the basic information of Table 13 is presented to the DM. Assuming that he/she is satisfied by the performance on objectives 1 and 2, but asks for an improvement on objective 3, i.e., a further cost reduction, even at the expense of the other two objectives, the following sets are formed:

- $G=\{$ objective 1 , objective 2 , objective 3$\}$;

- $G_{R}=\{$ objective 3$\}$;

- $\bar{G}_{R}=$ \{objective 1 , objective 2$\}$;

and the upper bound of objective 3 is updated as follows:

$$
h_{3}^{1}=h_{3}^{0}=15540 .
$$


Being members of set $\bar{G}_{R}$, the upper bounds of the other two objectives remain equal to their initial values, i.e.:

$$
\begin{aligned}
& h_{1}^{1}=h_{1}^{0}=722123, \\
& h_{2}^{1}=h_{2}^{0}=74559 .
\end{aligned}
$$

Then, the Problem (9) is solved for the third objective, which is the only member of set $G_{R}$ :

$$
\begin{aligned}
& \min g_{3}(\mathbf{x}) \\
& \text { subject to } \mathbf{x} \in X \\
& \qquad \begin{array}{l}
g_{1}(\mathbf{x}) \leq h_{1}^{1} \\
g_{2}(\mathbf{x}) \leq h_{2}^{1}
\end{array}
\end{aligned}
$$

and the feasible region of the decision problem is reduced as follows:

$$
X^{1}=X^{0} \cap\left\{\mathbf{x} \in R^{75} / g_{i}(x) \leq h_{i}^{1}, i=1,2,3\right\},
$$

with $X^{0}$ being the decision space $X$ of the initial problem.

\subsubsection{Phase Two-Iteration 1-Step 2}

On the basis of information from step 1 and assuming $s=9,10$ alternative profiles $a_{k}$, $k=0,1, \ldots, 9$, are generated, according to Equation (11), and presented to the DM in order to rank order them. Table 14 presents the profiles of these alternatives for each objective, along with their assumed ranking $r, r=1,2, \ldots, 10$.

Table 14. Reference set of alternatives and DM's ranking.

\begin{tabular}{ccccc}
\hline Profile & $\begin{array}{c}\text { Primary Energy } \\
\text { Consumption } \\
\text { (MJ/Year) }\end{array}$ & $\begin{array}{c}\text { Release of } \mathbf{C O}_{\mathbf{2}} \\
\text { Emissions } \\
\text { (kg CO } \mathbf{2} / \text { Year) }\end{array}$ & $\begin{array}{c}\text { Initial Investment } \\
\text { Cost } \\
(\boldsymbol{\epsilon})\end{array}$ & $\begin{array}{c}\text { DM's } \\
\text { Ranking }\end{array}$ \\
\hline$a_{0}$ & 13,593 & 810 & 15,540 & 3 \\
$a_{1}$ & 92,319 & 9004 & 14,650 & 2 \\
$a_{2}$ & 171,044 & 17,199 & 13,759 & 1 \\
$a_{3}$ & 249,770 & 25,393 & 12,868 & 4 \\
$a_{4}$ & 328,495 & 33,587 & 11,978 & 5 \\
$a_{5}$ & 407,221 & 41,782 & 11,087 & 6 \\
$a_{6}$ & 485,947 & 49,976 & 10,196 & 7 \\
$a_{7}$ & 564,672 & 58,171 & 9306 & 8 \\
$a_{8}$ & 643,398 & 66,365 & 8415 & 9 \\
$a_{9}$ & 722,123 & 74,559 & 7524 & 10 \\
\hline
\end{tabular}

The information of Table 14 is then used in UTASTAR, leading to the marginal utility functions graphically displayed in Figure 2, which define the global utility of the DM via the following additive function:

$$
u[\mathbf{g}(\mathbf{x})]=u_{1}\left(g_{1}(\mathbf{x})\right)+u_{2}\left(g_{2}(\mathbf{x})\right)+u_{3}\left(g_{3}(\mathbf{x})\right),
$$

or the equivalent:

$$
u[\mathbf{g}(\mathbf{x})]=0.300 u^{\prime}{ }_{1}\left(g_{1}(\mathbf{x})\right)+0.525 u^{\prime}{ }_{2}\left(g_{2}(\mathbf{x})\right)+0.175 u^{\prime}{ }_{3}\left(g_{3}(\mathbf{x})\right),
$$

where $u_{i}^{\prime}, i=1,2,3$, are the normalized, in the range $[0,1]$, values of the marginal utilities $u_{i}$, graphically displayed in Figure 3. 


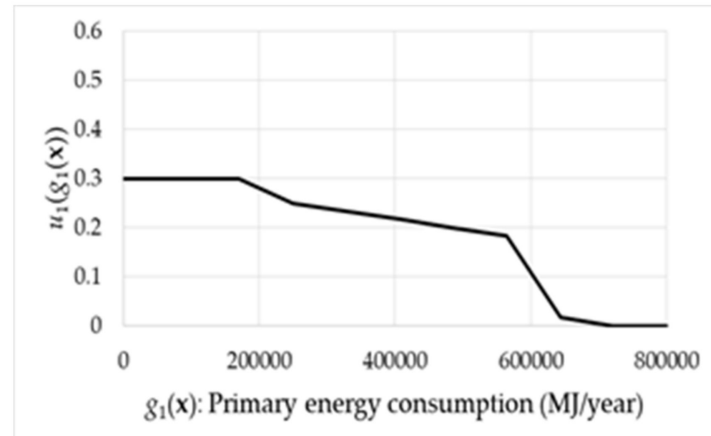

(a)

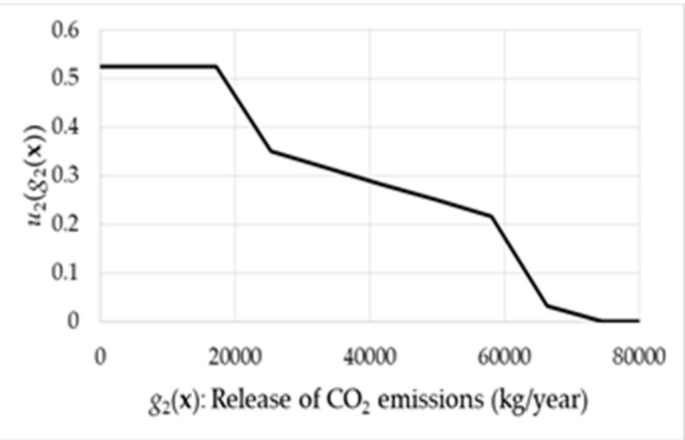

(b)

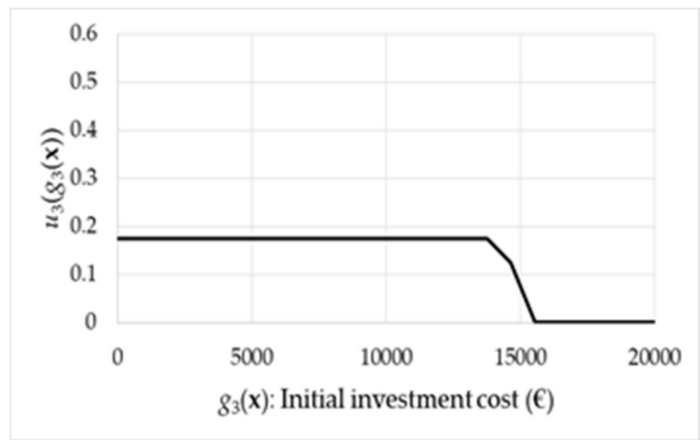

(c)

Figure 2. Marginal utility functions of: (a) Primary energy consumption; (b) release of $\mathrm{CO}_{2}$ emissions; (c) initial investment cost.

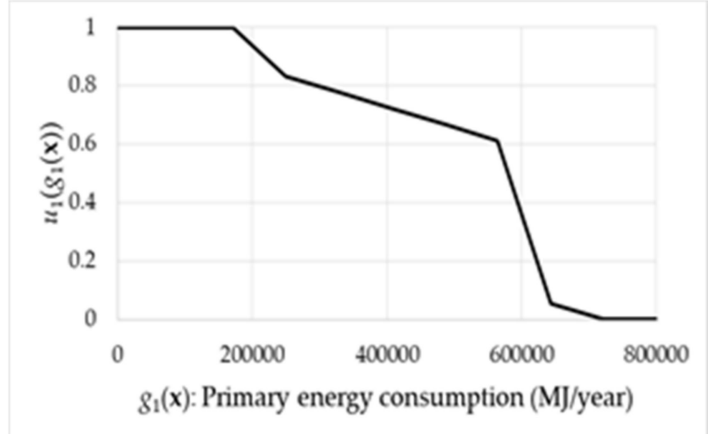

(a)

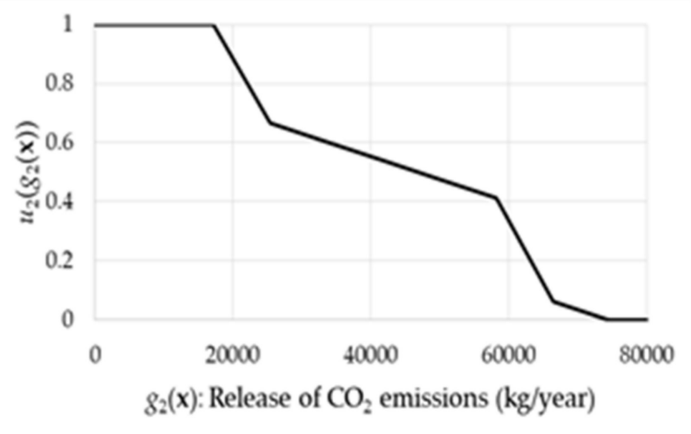

(b)

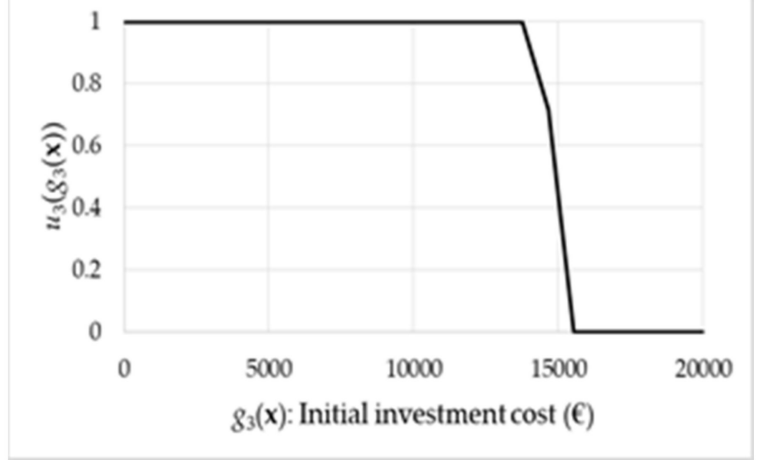

(c)

Figure 3. Normalized marginal utility functions of: (a) Primary energy consumption; (b) release of $\mathrm{CO}_{2}$ emissions; (c) initial investment cost. 


\subsubsection{Phase Two-Iteration 1-Step 3}

In this last step of phase two, the utility Function (18) or (19) is maximized over the decreased feasible solution space $X^{1}$, defined in (17). More specifically, the following problem:

$$
\begin{gathered}
\max u[\mathbf{g}(\mathbf{x})]=u_{1}\left(g_{1}(\mathbf{x})\right)+u_{2}\left(g_{2}(\mathbf{x})\right)+u_{3}\left(g_{3}(\mathbf{x})\right) \\
\text { subject to } \mathbf{x} \in X^{1}
\end{gathered}
$$

or its equivalent:

$$
\begin{gathered}
\max u[\mathbf{g}(\mathbf{x})]=0.300 u^{\prime}{ }_{1}\left(g_{1}(\mathbf{x})\right)+0.525 u^{\prime}{ }_{2}\left(g_{2}(\mathbf{x})\right)+0.175 u^{\prime}{ }_{3}\left(g_{3}(\mathbf{x})\right) \\
\text { subject to } \mathbf{x} \in X^{1}
\end{gathered}
$$

is solved.

The solution of any of the aforementioned problems generates the new compromise

\begin{tabular}{|c|c|c|c|}
\hline Information & $\begin{array}{c}\text { Primary Energy } \\
\text { Consumption } \\
\text { (MJ/Year) } \\
i=1\end{array}$ & $\begin{array}{c}\text { Release of } \mathrm{CO}_{2} \text { Emissions } \\
(\mathrm{kg} \mathrm{CO} / \text { Year) } \\
i=2\end{array}$ & $\begin{array}{l}\text { Initial Investment Cost } \\
\qquad(€) i=3\end{array}$ \\
\hline Ideal solution (lower limit) $l_{i}$ & 13,593 & 810 & 7524 \\
\hline New compromise solution $g_{i}^{1}$ & 166,640 & 17,199 & 11,147 \\
\hline Anti-ideal solution $h_{i}$ & 722,123 & 74,559 & 28187 \\
\hline New upper bound $h_{i}^{1}$ & 722,123 & 74,559 & 15,540 \\
\hline Rate of closeness to the ideal solution & $21.60 \%$ & $22.22 \%$ & $17.53 \%$ \\
\hline
\end{tabular}
solution, displayed in Table 15, the current iteration is terminated, and a new iteration starts from step 1.

Table 15. Basic information generated in iteration $q=1$ of phase two.

\subsubsection{Phase Two-Iteration 2-Step 1}

The second iteration of phase two starts with the results of Table 15 being presented to the DM. Apparently, the cost objective has been reduced as desired, coming closer to its ideal value; a rate of closeness $17.53 \%$ has been achieved, which is also reduced compared to its previous value (38.80\%). This improvement, however, has come at the expense of the other two objectives, the values of which, as well as their corresponding rates of closeness, present an increase.

If the consequences of the obtained solution are not satisfactory, the interaction with the DM should continue, like in the previous iteration, until reaching a satisfactory solution. Otherwise, the procedure stops here and the final choices made through this multi-phase procedure (see Table 16) are presented to the DM.

Table 16. Initial and final compromise solutions.

\begin{tabular}{ccc}
\hline Decisions and Criteria & Initial Compromise Solution & Final Compromise Solution \\
\hline Door type & 1 & 1 \\
Window type/subtype & $2 / 2$ & $2 / 1$ \\
Wall structure & 2 & 1 \\
Wall insulation thickness (m) & 0.07 & 0 \\
Wall insulation material & 3 & - \\
Ceiling structure & 2 & 2 \\
Ceiling insulation thickness (m) & 0.07 & 0.01 \\
Ceiling insulation material & 3 & 1 \\
Floor structure & 1 & 1 \\
Floor insulation thickness (m) & 0.07 & 0.07 \\
Floor insulation material & 3 & 1 \\
Heating system type & $\mathrm{EHC}$ & $\mathrm{EHC}$ \\
Heating system category/type & $1 / 3$ & $1 / 1$
\end{tabular}


Table 16. Cont.

\begin{tabular}{ccc}
\hline Decisions and Criteria & Initial Compromise Solution & Final Compromise Solution \\
\hline Cooling system type & - & - \\
Cooling system category/type & - & - \\
Hot water supply system type & NEW & NEW \\
Hot water supply system category/type & $2 / 2$ & $2 / 2$ \\
Solar collector category/type & $2 / 2$ & $1 / 1$ \\
$g_{1}$ : Primary energy consumption $(\mathrm{MJ} /$ year $)$ & 19,582 & 166,640 \\
$g_{2}$ : Release of $\mathrm{CO}_{2}$ emissions $(\mathrm{kg} \mathrm{CO} /$ year) & 1986 & 17,199 \\
$g_{3}$ : Initial investment cost $(€)$ & 15,540 & 11,147 \\
\hline
\end{tabular}

EHC: electrical system that will be used for both heating and cooling (see Table 8); NEW: non-electrical system that will be used only for hot water supply (see Table 10).

\section{Discussion}

The previous two sections presented an interactive mathematical programming approach to the problem of improving energy efficiency in buildings, and demonstrated its use via an example case study. The problem is difficult to solve as it involves multiple, competitive objectives, and a large number of decision variables, given the large number of available, alternative measures, which can be adopted in this respect. In addition, the solution of the problem requires the DM to express his/her preferences to the considered objectives, a fact that further increases the problem's complexity.

The approach proposed herein exploits the mathematical programming model proposed by Diakaki et al. [5] and the UTASTAR value elicitation method proposed by Siskos and Yannacopoulos [16] under an interactive decision framework, which has been developed following the rationale and principles of the decision-oriented method for multiobjective linear programming problems proposed by Siskos and Despotis [15]. The proposed framework assists the decision making procedure so that decisions are made, which comply with the value system of the DM, without the need to prescribe it beforehand.

The proposed approach can be also adopted in other decision settings within, but also beyond, the field of energy and environment. A similar approach, for example, lies on the basis of ADELAIS, an interactive computer program developed to support the search for a satisfactory solution in multi-objective linear programming problems, which has been used as a tool for the selection of stock portfolios [18]. In contrast, however, to both the initial conception in [15] and the ADELAIS program, the decision framework developed herein concerns a mixed-integer nonlinear mathematical programming problem, which aims at minimizing rather than maximizing the considered multiple objectives. This means that the overall framework can be adopted to any possible decision settings, should adequate care be taken to consider any potential particularities; e.g., in a case where objectives with a positive preference direction (e.g., comfort) should also be considered, to incorporate them, preserving at the same time the required cohesiveness of all considered objectives, their preference direction should be reversed by changing the sign of their corresponding functions. In addition, the mathematical programming formulation is quite flexible, allowing the incorporation of additional DM's objectives and preferences.

\section{Conclusions}

The study presented herein demonstrated the feasibility as well as the strengths of applying an interactive mathematical modelling approach to the problem of energy efficiency improvement. The application of such a systematic approach allows for the simultaneous consideration of all available combinations of alternative actions, the consideration of any logical, physical, technical, or other constraints that may apply, and the incorporation of the preferences and value system of the DM without having to explicitly prescribe them beforehand. In addition, the application of the proposed approach ensures that a single, final solution will be reached, which will be satisfactory, and thus acceptable by the corresponding DM. 
The proposed approach addresses the problem of improving energy efficiency in buildings in a systematic way. Thus, it can provide the basis for the development of a corresponding decision support system (DSS), which could assist the respective DAs in their difficult task of identifying, among the large volume of available measures, those that will satisfy the needs, requirements, and preferences of the DMs. According to Li et al. [19], there is still plenty of room for the enhancement of the existing relevant toolkits and the development of new ones, and the proposed approach provides the ground in this direction.

Author Contributions: Conceptualization, C.D. and E.G.; investigation, C.D. and E.G.; writingoriginal draft, C.D. and E.G.; writing - review and editing, C.D. and E.G. All authors have read and agreed to the published version of the manuscript.

Funding: This research received no external funding.

Institutional Review Board Statement: Not applicable.

Informed Consent Statement: Not applicable.

Data Availability Statement: Not applicable.

Conflicts of Interest: The authors declare no conflict of interest.

\section{Appendix A. The UTASTAR Method}

The UTASTAR method proposed by Siskos and Yannacopoulos [16] is a variation of the UTA method, which aims at inferring a set of additive value functions from a given ranking on a reference set $A_{R}$ of alternative actions $a \in A_{R}$.

UTASTAR assumes an unweighted additive value function of the form:

$$
u(\mathbf{g})=\sum_{i=1}^{n} u_{i}\left(g_{i}\right)
$$

under the normalization constraints:

$$
\left\{\begin{array}{l}
\sum_{i=1}^{n} u_{i}\left(g_{i}^{*}\right)=1 \\
u_{i}\left(g_{i *}\right)=0
\end{array} \quad \forall i=1,2, \ldots, n\right.
$$

where $n$ is the number of criteria; $\left\{g_{1}, g_{2}, \ldots, g_{n}\right\}$ is the set of criteria; $\left[g_{i}^{*}, g_{i *}\right]$ is the evaluation scale of criterion $i$, with $i=1,2, \ldots, n$ and $g_{i *}, g_{i}^{*}$ the worst and best level of criterion $i$, respectively; $u_{i}$ is the marginal value function of criterion $i$.

On the basis of the additive $\operatorname{Model}(\mathrm{A} 1)$ and (A2), the value of each alternative $a \in A_{R}$ may be expressed as:

$$
u[\mathbf{g}(a)]=\sum_{i=1}^{n} u_{i}\left[g_{i}(a)\right]-\sigma^{+}(a)-\sigma^{-}(a)
$$

where $\sigma^{+}, \sigma^{-}$are the overestimation and underestimation errors, respectively.

In addition, linear interpolation is used in order to estimate the corresponding marginal value functions in a piecewise linear form. More specifically, for each criterion $i$, the interval $\left[g_{i}^{*}, g_{i *}\right]$ is first cut into $\left(\alpha_{i}-1\right)$ equal intervals, where the points $g_{i}^{j}$ are given by the following formula:

$$
g_{i}^{j}=g_{i *}+\frac{j-1}{\alpha_{i}-1}\left(g_{i}^{*}-g_{i *}\right) \forall j=1,2, \ldots, \alpha_{i}
$$


Then, the marginal value of each action $a \in A_{R}$, for which $g_{i}(a) \in\left[g_{i}^{j}, g_{i}^{j+1}\right]$ is approximated by the following linear interpolation:

$$
u_{i}\left[g_{i}(a)\right]=u\left(g_{i}^{j}\right)+\frac{g_{i}(a)-g_{i}^{j}}{g_{i}^{j+1}-g_{i}^{j}}\left[u\left(g_{i}^{j+1}\right)-u\left(g_{i}^{j}\right)\right]
$$

Furthermore, the set of reference actions $A_{R}=\left\{a_{1}, a_{2}, \ldots, a_{m}\right\}$ is rearranged so that $a_{1}$ is the action with the best ranking, $a_{m}$ is the action with the worst ranking, and for each pair of consecutive actions $\left(a_{k}, a_{k+1}\right)$, either $a_{k} \succ a_{k+1}$ (preference) or $a_{k} \sim a_{k+1}$ (indifference) holds, thus if

$$
\Delta\left(a_{k}, a_{k+1}\right)=u\left[\mathbf{g}\left(a_{k}\right)\right]-u\left[\mathbf{g}\left(a_{k+1}\right)\right],
$$

one of the following holds:

$$
\left\{\begin{array}{l}
\Delta\left(a_{k}, a_{k+1}\right) \geq \delta \text { if } a_{k} \succ a_{k+1} \\
\Delta\left(a_{k}, a_{k+1}\right)=0 \text { if } a_{k} \sim a_{k+1}
\end{array},\right.
$$

where $\delta$ is a small positive number, which, however, allows the equivalence discrimination of two actions, which are successive in the ranking.

A final important modification of the UTASTAR method concerns the monotonicity constraints of the criteria that are taken into account through the following transformations:

$$
w_{i j}=u_{i}\left(g_{i}^{j+1}\right)-u_{i}\left(g_{i}^{j}\right) \geq 0 \forall i=1,2, \ldots, n \text { and } j=1,2, \ldots, \alpha_{i}-1,
$$

which allow the replacement of the monotonicity conditions for $u_{i}$ with non-negative constraints for the variables $w_{i j}$.

Based on the above, given the ranking over a reference set $A_{R}$ of alternative actions $a \in A_{R}$, the UTASTAR method can be implemented via the following four steps:

1. The global value of all reference actions $u\left[\mathbf{g}\left(a_{k}\right)\right], k=1,2, \ldots, m$, is first expressed in terms of the marginal values $u_{i}\left(g_{i}\right)$, and then in terms of the variables $w_{i j}$, according to (A8), through the following relationships:

$$
\left\{\begin{array}{l}
u_{i}\left(g_{i}^{1}\right)=0 \forall i=1,2, \ldots, n \\
u_{i}\left(g_{i}^{j}\right)=\sum_{t=1}^{j-1} w_{i j} \forall i=1,2, \ldots, n \text { and } \forall j=2,3, \ldots, \alpha_{i}-1
\end{array}\right.
$$

2. For each pair of actions, which are consecutive in the given ranking, error terms are introduced using the following relationship:

$$
\Delta\left(a_{k}, a_{k+1}\right)=u\left[\mathbf{g}\left(a_{k}\right)\right]-\sigma^{+}\left(a_{k}\right)+\sigma^{-}\left(a_{k}\right)-u\left[\mathbf{g}\left(a_{k+1}\right)\right]+\sigma^{+}\left(a_{k+1}\right)-\sigma^{-}\left(a_{k+1}\right)
$$

3. The following linear programming problem is solved:

$$
\begin{aligned}
& \min z=\sum_{k=1}^{m}\left[\sigma^{+}\left(a_{k}\right)+\sigma^{-}\left(a_{k}\right)\right] \\
& \left.\begin{array}{rl}
\text { subject to } \Delta\left(a_{k}, a_{k+1}\right) \geq \delta \text { if } a_{k} \succ a_{k+1} \\
\Delta\left(a_{k}, a_{k+1}\right)=0 \text { if } a_{k} \sim a_{k+1}
\end{array}\right\} \forall r \\
& \sum_{i=1}^{n} \sum_{j=1}^{\alpha_{i}-1} w_{i j}=1 \\
& w_{i j} \geq 0, \sigma^{+}\left(a_{k}\right) \geq 0, \sigma^{-}\left(a_{k}\right) \geq 0 \forall i, j, k
\end{aligned}
$$


4. The existence of multiple or near optimal solutions of the Problem (A11) is examined (stability analysis), and the mean additive value function of those (near) optimal solutions is found, which maximize the objective functions:

$$
u_{i}\left(g_{i}^{*}\right)=\sum_{j=1}^{\alpha_{i}-1} w_{i t} \forall i=1,2, \ldots, n
$$

on the polyhedron of the constraints of the Problem (A11), bounded by the following additional constraint:

$$
\sum_{k=0}^{m}\left[\sigma^{+}\left(a_{k}\right)+\sigma^{-}\left(a_{k}\right)\right] \leq z *+\varepsilon
$$

where $z *$ is the optimal value of Problem (A11) and $\varepsilon$ is a very small positive number.

\section{Appendix B. The Multi-Objective Decision Model of the Application Example}

This Appendix provides an overview of the mathematical model of the considered multi-objective problem. The details of the model can be found in [5].

Appendix B.1. Parameters and Decision Variables

Table A1. Doors-related parameters and data.

\begin{tabular}{cc}
\hline Parameters & Description \\
\hline$D R$ & Number of building's doors; here $D R=1$ \\
$d r$ & Index to $D R ; d r=1, \ldots, D R$ \\
$A_{d r}^{D O R}$ & Area of door $d r\left(\mathrm{~m}^{2}\right) ;$ here $A d r=6$ \\
$b_{d r}^{D O R}$ & Temperature correction factor of construction part $d r ;$ here $b d r$ \\
$V$ & Number of available door types \\
$v$ & Index to $V ; v=1, \ldots, V$ \\
$U_{v}^{D O R}$ & Thermal transmittance of door type $\left(\mathrm{W} / \mathrm{m}^{2} \mathrm{~K}\right)$ \\
$C_{v}^{D O R}$ & Cost of door type $v\left(€ / \mathrm{m}^{2}\right)$ \\
\hline
\end{tabular}

Table A2. Windows-related parameters and data.

\begin{tabular}{cc}
\hline Parameters & Description \\
\hline$W N$ & Number of building's windows; here $W N=1$ \\
$w n$ & Index to $W N ; w n=1, \ldots, W N$ \\
$A_{w n}^{W I N}$ & Area of window $w n\left(\mathrm{~m}^{2}\right) ;$ here $A_{w n}^{W I N}=6$ \\
$b_{w n}^{W I N}$ & Temperature correction factor of construction part $w n ;$ here $b_{w n}^{W I N}=1$ \\
$F_{F, w n}$ & Frame factor of window $w n(\%) ;$ here $F_{F, w n}=0.7$ \\
$F_{S, w n}$ & Correction factor for shading of window $w n(\%) ;$ here $F_{S, w n}=1$ \\
$F_{C M, w n}$ Correction factor for movable devices of window $w n(\%) ;$ here $F_{C M, w n}=1$ \\
$S$ & Number of available window types \\
$S$ & Index to $S ; s=1, \ldots, S$ \\
$T_{S}$ & Number of available sub-types of window type $s$ \\
$t$ & Index to $T_{S} ; t=1, \ldots, T_{S}, \forall s=1, \ldots, S$ \\
$g_{s t}^{W I N}$ & Effective total solar energy transmittance of window sub-type $t(\%)$ \\
$U_{s t}^{W I N}$ & Thermal transmittance of window sub-type $t\left(\mathrm{~W} / \mathrm{m}^{2} \mathrm{~K}\right)$ \\
$C_{s t}^{W I N}$ & Cost of window sub-type $t\left(€ / \mathrm{m}^{2}\right)$ \\
\hline
\end{tabular}


Table A3. Walls-related parameters and data.

\begin{tabular}{|c|c|}
\hline Parameters & Description \\
\hline$W L$ & Number of walls; here $W L=4$ \\
\hline$w l$ & Index to $W L ; w l=1, \ldots, W L$ \\
\hline$A_{w l}^{W A L}$ & Area of wall $w l\left(\mathrm{~m}^{2}\right)$; here $A_{1}^{W A L}=A_{2}^{W A L}=30$ and $A_{3}^{W A L}=A_{4}^{W A L}=24$ \\
\hline$b_{w l}^{W A L}$ & Temperature correction factor of construction part $w l ;$ here $b_{w l}^{W A L}=1$ \\
\hline$W$ & Number of available wall structures \\
\hline$w$ & Index to $W ; w=1, \ldots, W$ \\
\hline$K W L_{w}$ & Number of known layers of structure $w$, regarding material and thickness \\
\hline$k w l$ & Index to $K W L_{w} ; k w l=1, \ldots, K W L_{w}, \forall w=1, \ldots, W$ \\
\hline$d_{w, k w l}^{d W A L}$ & Thickness of known layer $k w l$ of wall structure $w(\mathrm{~m})$ \\
\hline$k k_{w, k w l}^{m, w h}$ & Thermal conductivity of material of known layer $k w l$ of wall structure $w(\mathrm{~W} / \mathrm{mK})$ \\
\hline$C K_{w, k w l}^{m W L L}$ & Cost of material of known layer $k w l$ of wall structure $w\left(€ / \mathrm{m}^{3}\right)$ \\
\hline$Y_{w}^{w, n w}$ & Number of unknown layers of structure $w$; here $Y_{w}=1$ (insulation layer) \\
\hline$y$ & Index to $Y_{w} ; y=1, \ldots, Y_{w}, \forall w=1, \ldots, W$ \\
\hline$d_{\max , w y}^{W A L}$ & Maximum permissible thickness of layer $y$ of structure $w(\mathrm{~m})$; here $d_{\max , w y}^{W A L}=0.1$ \\
\hline$C_{w y}$ & Number of available materials for layer $y$ of structure $w$ \\
\hline$c$ & Index to $C_{w y} ; c=1, \ldots, C_{y w}, \forall\left(y=1, \ldots, Y_{w}, \forall w=1, \ldots, W\right)$ \\
\hline$k_{w y c}^{m W A L}$ & Thermal conductivity of material $c$ of unknown layer $y$ of structure $w(\mathrm{~W} / \mathrm{mK})$ \\
\hline$C_{w y c}^{m W A L}$ & Cost of material $c$ of unknown layer $y$ of structure $w\left(€ / \mathrm{m}^{3}\right)$ \\
\hline
\end{tabular}

Table A4. Ceilings-related parameters and data.

\begin{tabular}{|c|c|}
\hline Parameters & Description \\
\hline$C E$ & Number of ceilings; here $C E=1$ \\
\hline ce & Index to $C E ; c e=1, \ldots, C E$ \\
\hline$A_{C e}^{C E I L}$ & Area of ceiling $c e\left(\mathrm{~m}^{2}\right) ;$ here $A_{c e}^{C E I L}=100$ \\
\hline$b_{c e}^{C E I L}$ & Temperature correction factor of construction part $c e$; here $b_{c e}^{C E I L}=1$ \\
\hline$D$ & Number of available ceiling structures \\
\hline$d$ & Index to $D ; d=1, \ldots, D$ \\
\hline$K C L_{d}$ & Number of known layers of structure $d$, regarding material and thickness \\
\hline$k c l$ & Index to $K C L_{d} ; k c l=1, \ldots, K C L_{d}, \forall d=1, \ldots, D$ \\
\hline$d_{d k C l}^{d C E I L}$ & Thickness of known layer $k c l$ of structure $d(\mathrm{~m})$ \\
\hline$k k_{d, k c l}^{m, k C I L}$ & Thermal conductivity of material of known layer $k c l$ of structure $d(\mathrm{~W} / \mathrm{mK})$ \\
\hline$C K_{d, k c l}^{m C E L}$ & Cost of material of known layer $k c l$ of structure $d\left(€ / \mathrm{m}^{3}\right)$ \\
\hline$F_{d}$ & Number of unknown layers of structure $d$; here $F_{d}=1$ (insulation layer) \\
\hline$f^{n}$ & Index to $F_{d} ; f=1, \ldots, F_{d}, \forall d=1, \ldots, D$ \\
\hline$d_{\max , d f}^{C E I L}$ & Maximum permissible thickness of layer $f$ of structure $d(\mathrm{~m})$; here $d_{\max , d f}^{C E I L}=0.1$ \\
\hline$A_{d f}$ & Number of available materials for layer $f$ of structure $d$ \\
\hline$a$ & Index to $A_{d f} ; a=1, \ldots, A_{d f}, \forall\left(f=1, \ldots, F_{d} \forall d=1, \ldots, D\right)$ \\
\hline$k_{d f a}^{m C E I L}$ & Thermal conductivity of material $a$ of unknown layer $f$ of structure $d(\mathrm{~W} / \mathrm{mK})$ \\
\hline$C_{d f a}^{m C E I L}$ & Cost of material $a$ of unknown layer $f$ of structure $d\left(€ / \mathrm{m}^{3}\right)$ \\
\hline
\end{tabular}

Table A5. Floors-related parameters and data.

\begin{tabular}{cc}
\hline Parameters & Description \\
\hline$F L$ & Number of floors; here $f l=1$ \\
$f l$ & Index to $F L ; f l=1, \ldots, F L$ \\
$A_{f l}^{F L O}$ & Area of floor $f l\left(\mathrm{~m}^{2}\right) ;$ here $A_{f l}^{F L O}=100$ \\
$b_{f l}^{F L O}$ & Temperature correction factor of construction part $f l ;$ here $b_{f l}^{F L O}=1$ \\
$H$ & Number of available floor structures \\
$h$ & Index to $H ; h=1, \ldots, H$ \\
$K F L_{h}$ & Number of known layers of structure $h$, regarding material and thickness \\
$k f l$ & Index to $K F L_{h} ; k f l=1, \ldots, K F L_{h}, \forall h=1, \ldots, H$ \\
\hline
\end{tabular}


Table A5. Cont.

\begin{tabular}{cc}
\hline Parameters & Description \\
\hline$d_{h, k f l}^{d F L O}$ & Thickness of known layer $k f l$ of structure $h(\mathrm{~m})$ \\
$k k_{h, k f l}^{m F L O}$ & Thermal conductivity of material of known layer $k f l$ of structure $h(\mathrm{~W} / \mathrm{mK})$ \\
$C K_{h, k f l}^{m F L O}$ & Cost of material of known layer $k f l$ of structure $h\left(€ / \mathrm{m}^{3}\right)$ \\
$E_{h}$ & Number of unknown layers of structure $h ;$ here $E_{h}=1($ insulation layer $)$ \\
$e$ & Index to $E_{h} ; e=1, \ldots, E_{h}, \forall h=1, \ldots, H$ \\
$d_{\max , h e}^{F L O}$ & Maximum permissible thickness of layer $e$ of structure $h(\mathrm{~m}) ;$ here $d_{\text {max }}^{F L O}=0.1$ \\
$G_{h e}$ & Number of available materials for layer $e$ of structure $h$ \\
$g$ & Index to $G_{h e} ; g=1, \ldots, G_{h e}, \forall\left(e=1, \ldots, E_{h} \forall h=1, \ldots, H\right)$ \\
$k_{h e g}^{m F L O}$ & Thermal conductivity of material $g$ of unknown layer $e$ of structure $h(\mathrm{~W} / \mathrm{mK})$ \\
$C_{h e g}^{m F L O}$ & Cost of material $g$ of unknown layer $e$ of structure $h\left(€ / \mathrm{m}^{3}\right)$ \\
\hline
\end{tabular}

Table A6. Heating-only systems' parameters and data.

\begin{tabular}{cc}
\hline Parameters & Description \\
\hline$E H I$ & Number of available electrical heating systems' categories \\
$e h i$ & Index to $E H I ;$ ehi $=1, \ldots, E H I$ \\
$E H J_{e h i}$ & Number of available systems of category ehi \\
$e h j$ & Index to $E H J_{e h i} ;$ hhj $=1, \ldots, E H J_{e h i}, \forall e h i=1, \ldots, E H I$ \\
$e_{e h i, e h j}^{E H}$ & Generation efficiency of system $e h j$ of category $e h i(\%)$ \\
$C S T_{e h i, e h j}^{E H}$ & Installation cost of system ehj of category ehi $(€)$ \\
$N E H I$ & Number of available non-electrical heating systems' categories \\
$n e h i$ & Index to $N E H I ; n e h i=1, \ldots, N E H I$ \\
$N E H J_{n e h i}$ & Number of available systems of category nehi \\
$n e h j$ & Index to $N E H J_{n e h i} ;$ nehj $=1, \ldots, N E H J_{n e h i}, \forall \forall n e h i=1, \ldots, N E H I$ \\
$e_{n e h i, n e h j}^{N E H}$ & Generation efficiency of system nehj of category nehi $(\%)$ \\
$C S T_{n e h i, n e h j}^{N E H}$ & Installation cost of system $n e h j$ of category nehi $(€)$ \\
$F U_{n e h i, n e h j, f u e l}^{N E H}$ & Parameter; equals 1, if system $n e h j$ of category nehi uses fuel fuel, else equals 0 \\
\hline
\end{tabular}

Table A7. Cooling-only systems' parameters and data.

\begin{tabular}{cc}
\hline Parameters & Description \\
\hline$E C I$ & Number of available electrical cooling systems categories \\
$e c i$ & Index to $E C I ; e c i=1, \ldots, E C I$ \\
$E C J_{e c i}$ & Number of available systems of category $e c i$ \\
$e c j$ & Index to $E C J_{e c i} ; e c j=1, \ldots, E C J_{e c i}, \forall e c i=1, \ldots, E C I$ \\
$e_{e c i, e c j}^{C}$ & Generation efficiency of system $e c j$ of category $e c i(\%)$ \\
$C S T_{e c i, e c j}^{C}$ & Installation cost of system $e c j$ of category $e c i(€)$ \\
\hline
\end{tabular}

Table A8. Domestic hot water (DHW) supply-only systems' parameters and data.

\begin{tabular}{cc}
\hline Parameters & Description \\
\hline$E W I$ & Number of available electrical DHW systems' categories \\
$e w i$ & Index to $E W I ;$ ewi $=1, \ldots, E W I$ \\
$E W J_{e w i}$ & Number of available systems of category ewwi \\
$e w j$ & Index to $E W J_{e w i} ;$ ewj $=1, \ldots, E W J_{e w i}, \forall e w i=1, \ldots, E W I$ \\
$e_{e w i, e w j}^{E W}$ & Generation efficiency of system $e w j$ of category $e w i(\%)$ \\
$C S T_{e \text { ewi,ewj }}^{E W}$ & Installation cost of system $e w j$ of category ewi $(€)$ \\
$N E W I$ & Number of available non-electrical $D H W$ systems' categories \\
$n e w i$ & Index to $N E W I ; n e w i=1, \ldots, N E W I$ \\
$N E W J_{n e w i}$ & Number of available systems of category newi \\
$n e w j$ & Index to $N E W J_{\text {newi }} ;$ newj $=1, \ldots, N E W J_{\text {newi }}, \forall$ newi $=1, \ldots, N E W I$ \\
\hline
\end{tabular}


Table A8. Cont.

\begin{tabular}{cc}
\hline Parameters & Description \\
\hline$e_{\text {newi,newj }}^{N E W}$ & Generation efficiency of system newj of category newi (\%) \\
$C S T_{\text {newi,newj }}^{N E W}$ & Installation cost of system newj of category newi ( $€$ ) \\
$F U_{\text {newi,newj,fuel }}^{N E W}$ & Parameter; equals 1, if system newj of category newi uses fuel fuel, else equals 0 \\
\hline
\end{tabular}

Table A9. Combined heating-cooling systems' parameters and data.

\begin{tabular}{cc}
\hline Parameters & Description \\
\hline$E H C I$ & Number of available combined electrical heating-cooling systems' categories \\
$e h c i$ & Index to $E h C I ;$ ehci $=1, \ldots, E H C I$ \\
$E H C J_{e h c i}$ & Number of available systems of category ejci \\
$e h c j$ & Index to $E H C J_{\text {ehci }} ;$ ehcj $=1, \ldots, E H C J_{\text {ehci }}, \forall e h c i=1, \ldots, E h C I$ \\
$e_{e h c i, e h c j}^{H C}$ & Generation efficiency of system $e h c j$ of category $e h c i(\%)$ \\
$C S T_{e h c i, e h c j}^{\mathrm{HC}}$ & Installation cost of system $e c j$ of category eci $(€)$ \\
\hline
\end{tabular}

Table A10. Combined heating-DHW systems' parameters and data.

\begin{tabular}{|c|c|}
\hline Parameters & Description \\
\hline $\begin{array}{l}\text { EHWI } \\
\text { ehwi }\end{array}$ & $\begin{array}{l}\text { Number of available combined electrical heating-DHW systems' categories } \\
\text { Index to EHWI; ehwi }=1, \ldots, E H W I\end{array}$ \\
\hline$E H W J_{e h w i}$ & Number of available systems of category ehwi \\
\hline $\begin{array}{l}\text { ehwj } \\
e_{\rho h w i}^{E H W}\end{array}$ & $\begin{array}{c}\text { Index to } E H W J_{\text {ehwi }} ; \text { ehwj }=1, \ldots, E H W J_{\text {ehwi }}, \forall \text { ehwi }=1, \ldots, E H W I \\
\text { Generation efficiency of system ehwj of category ehwi (\%) }\end{array}$ \\
\hline CST ehwi,ehwj & Installation cost of system ehwj of category ehwi $(€)$ \\
\hline NEHWI & $\begin{array}{c}\text { Number of available non-electrical combined heating-DHW } \\
\text { systems' categories }\end{array}$ \\
\hline nehwi & Index to NEHWI; nehwi $=1, \ldots, N E H W I$ \\
\hline$N E H W J_{n e h w i}$ & Number of available systems of category nehwi \\
\hline nehwj & $\begin{array}{c}\text { Index to NEHWJ } J_{\text {nehwi }} ; \\
n e h w j=1, \ldots, N E H W J_{n e h w i}, \forall n e h w i=1, \ldots, N E H W I\end{array}$ \\
\hline$e_{n e h w i, n e h w j}^{N E H W}$ & Generation efficiency of system nehwj of category nehwi (\%) \\
\hline$C S T_{n e h w i, n e h w j}^{N E H W}$ & Installation cost of system nehwj of category nehwi $(€)$ \\
\hline$F U_{\text {nehwi,nehwj,fuel }}^{N E H W}$ & $\begin{array}{c}\text { Parameter; equals } 1 \text {, if system nehwj of category nehwi uses fuel fuel, else } \\
\text { equals } 0\end{array}$ \\
\hline
\end{tabular}

Table A11. Solar collectors' parameters and data.

\begin{tabular}{cc}
\hline Parameters & Description \\
\hline$A_{S L C}$ & Area of solar collector $\left(\mathrm{m}^{2}\right)$; here $A_{S L C}=2$ \\
$F_{S, S L C}$ & Correction factor for shading of solar collector $(\%) ;$ here $F_{S, S L C}=1$ \\
$U$ & Number of available solar collectors systems' categories \\
$u$ & Index to $U ; u=1, \ldots, U$ \\
$B_{u}$ & Number of available solar collectors systems of category $u$ \\
$b$ & Index to $B_{u} ; b=1, \ldots, B_{u}, \forall u=1, \ldots, U$ \\
$e_{u b}^{S L C}$ & Generation efficiency of system $b$ of category $u(\%)$ \\
$C S T_{u b}^{S L C}$ & Installation cost of system $b$ of category $u\left(€ / \mathrm{m}^{2}\right)$ \\
\hline
\end{tabular}


Table A12. Fuel and emissions-related parameters and data ${ }^{1}$.

\begin{tabular}{|c|c|}
\hline Parameters & Description \\
\hline FUEL & Number of fuels available for heating and DHW; here FUEL $=2$ \\
\hline fuel & Index to FUEL; fuel $=1, \ldots$, FUEL; here $f u e l=1$ is oil and $f u e l=2$ is gas \\
\hline$F_{f u e l}$ & $\begin{array}{l}\text { Conversion factor of fuel fuel to } \mathrm{CO}_{2} \text { emissions }\left(\mathrm{kg} \text { of } \mathrm{CO}_{2} / \mathrm{kg} \text { of fuel }\right) \text {; here } \\
\qquad F_{1}=3.142 \text { and } F_{\text {fuel }}=2.715\end{array}$ \\
\hline$L H P_{f u e l}$ & $\begin{array}{l}\text { Conversion factor of fuel fuel to energy }(\mathrm{MJ} / \mathrm{kg} \text { of fuel); here } \\
\qquad L H P_{1}=42.912 \text { and } L H P_{2}=49.788\end{array}$ \\
\hline$F_{\text {station }}$ & $\begin{array}{l}\text { Emissions factor of electricity producing station }\left(\mathrm{kg} \text { of } \mathrm{CO}_{2} / \mathrm{MJ}\right) \text {; here } \\
\qquad F_{\text {station }}=0.295\end{array}$ \\
\hline$n_{e l}$ & Return rate of electricity producing stations; here $n_{e l}=0.35$ \\
\hline \multicolumn{2}{|c|}{${ }^{1}$ Parameter values have been adopted from [5]. } \\
\hline Parameters & Description \\
\hline$n$ & Month index; $n=1, \ldots, 12 ; 1$ corresponds to January, 2 to February, etc. \\
\hline $\begin{array}{c}T_{n} \\
\theta_{E, n}\end{array}$ & $\begin{array}{l}\text { Duration of month } n(\mathrm{~s}) \\
\text { Average external temperature at building's location in month } n\left({ }^{\circ} \mathrm{C}\right)\end{array}$ \\
\hline$I_{S L, w n, n}$ & Solar radiation on window $w n$ in month $n\left(\mathrm{MJ} / \mathrm{m}^{2} / \mathrm{month}\right)$ \\
\hline$I_{S L, S L C, n}$ & Solar radiation on solar collector in month $n\left(\mathrm{MJ} / \mathrm{m}^{2} / \mathrm{month}\right)$ \\
\hline$\rho_{\text {air }}$ & Air density at building's location $\left(\mathrm{kg} / \mathrm{m}^{3}\right)$ \\
\hline$c_{\text {air }}$ & Air heat at building's location $\left(\mathrm{J} / \mathrm{kg}^{\circ} \mathrm{C}\right)$ \\
\hline$V_{\text {air }}$ & Air volume $\left(\mathrm{m}^{3}\right)$ \\
\hline
\end{tabular}

Table A14. Parameters and data describing comfort-related user preferences and foreseen operational conditions of the building.

\begin{tabular}{|c|c|}
\hline Parameters & Description \\
\hline$\theta_{I H}$ & Internal design temperature during heating season $\left({ }^{\circ} \mathrm{C}\right)$; here $\theta_{I H}=21$ \\
\hline$\theta_{I C}$ & Internal design temperature during cooling season $\left({ }^{\circ} \mathrm{C}\right)$; here $\theta_{I C}=26$ \\
\hline$H S_{n}$ & $\begin{array}{l}\text { Parameter; equals 1, if heating is required for month } n \text {, else equals } 0 \text {; here } \\
H S_{n}=1 \text { for } n=1,2,3,4,10,11,12 \text { and } H S_{n}=0 \text { for } n=5,6,7,8,9\end{array}$ \\
\hline$C S_{n}$ & $\begin{array}{l}\text { Parameter; equals } 1 \text {, if cooling is required for month } n \text {, else equals } 0 \text {; here } \\
\qquad C S_{n}=1 \text { for } n=6,7,8,9 \text { and } C S_{n}=0 \text { for } n=1,2,3,4,5,10,11,12\end{array}$ \\
\hline$W S_{n}$ & $\begin{array}{l}\text { Parameter; equals } 1 \text {, if hot water supply is required for month } n \text {, else } \\
\text { equals } 0 ; \text { here } W S_{n}=1 \forall n=1,2, \ldots, 12\end{array}$ \\
\hline$Q_{A I N H G}$ & Average monthly heat gains $(\mathrm{W}) ;$ here $Q_{A I N H G}=8400^{1}$ \\
\hline$Q_{d h w u}$ & $\begin{array}{l}\text { Average energy requirements for hot water use (MJ/month); here } \\
\qquad Q_{d h w u}=425^{1}\end{array}$ \\
\hline \multicolumn{2}{|c|}{$\begin{array}{l}\text { Rough estimates assuming } 4 \text { inhabitants in the building [5]. } \\
\end{array}$} \\
\hline Variable & Description \\
\hline$x_{v}^{D O R}$ & Doors choice; equals 1 , if type $v$ is selected, else equals 0 \\
\hline$x_{s t}^{W I N}$ & Windows choice; equals 1 , if subtype $t$ of type $s$ is selected, else equals 0 \\
\hline$x_{w}^{W W A L}$ & Wall structure choice; equals 1 , if structure $w$ is selected, else equals 0 \\
\hline$x_{w y c}^{m W A L}$ & $\begin{array}{c}\text { Wall material choice; equals } 1 \text {, if material } c \text { is selected for layer } y \text { of wall } \\
\text { structure } w \text {, else equals } 0\end{array}$ \\
\hline$x_{w y}^{d W A L}$ & Thickness of material added in layer $y$ of wall structure $w(\mathrm{~m})$ \\
\hline$x_{d}^{C E I L}$ & Ceiling structure choice; equals 1 , if structure $d$ is selected, else equals 0 \\
\hline$x_{d f a}^{m C E I L}$ & $\begin{array}{c}\text { Ceiling material choice; equals } 1 \text {, if material } a \text { is selected for layer } f \text { of } \\
\text { ceiling structure } d \text {, else equals } 0\end{array}$ \\
\hline
\end{tabular}


Table A15. Cont.

\begin{tabular}{|c|c|}
\hline Variable & Description \\
\hline$x_{d f}^{d C E I L}$ & Thickness of material added in layer $f$ of ceiling structure $d(\mathrm{~m})$ \\
\hline$x_{h}^{F L O}$ & Floor structure choice; equals 1 , if structure $h$ is selected, else equals 0 \\
\hline$x_{\text {heg }}^{m F L O}$ & $\begin{array}{c}\text { Floor material choice; equals } 1 \text {, if material } g \text { is selected for layer } e \text { of floor } \\
\text { structure } h \text {, else equals } 0\end{array}$ \\
\hline$x_{h e}^{d F L O}$ & Thickness of material added in layer $e$ of floor structure $h(\mathrm{~m})$ \\
\hline$x_{\text {ehi,ehj }}^{E H}$ & $\begin{array}{c}\text { Electrical heating system choice; equals } 1 \text {, if system ehj of category ehi is } \\
\text { selected, else equals } 0\end{array}$ \\
\hline$x_{n e h i, n e h j}^{N E H}$ & $\begin{array}{l}\text { Non-electrical heating system choice; equals } 1 \text {, if system nehj of category } \\
n e h i \text { is selected, else equals } 0\end{array}$ \\
\hline$x_{e c i, e c j}^{E C}$ & $\begin{array}{c}\text { Electrical cooling system choice; equals } 1 \text {, if system ecj of category eci is } \\
\text { selected, else equals } 0\end{array}$ \\
\hline$x_{e w i, e w j}^{E W}$ & $\begin{array}{c}\text { Electrical DHW system choice; equals } 1 \text {, if system ewj of category ewi is } \\
\text { selected, else equals } 0\end{array}$ \\
\hline$x_{n e w i, n e w j}^{N E W}$ & $\begin{array}{l}\text { Non-electrical DHW system choice; equals } 1 \text {, if system newj of category } \\
\text { newi is selected, else equals } 0\end{array}$ \\
\hline$x_{\text {ehci,ehcj }}^{E H C}$ & $\begin{array}{c}\text { Electrical heating-cooling system choice; equals } 1 \text {, if system ehcj of } \\
\text { category ehci is selected, else equals } 0\end{array}$ \\
\hline$x_{\text {ehwi,ehwj }}^{E H W}$ & $\begin{array}{c}\text { Electrical heating-DHW system choice; equals 1, if system ehwj of } \\
\text { category ehwi is selected, else equals } 0\end{array}$ \\
\hline$x_{n e h w i, n e h w j}^{N E H W}$ & $\begin{array}{c}\text { Non-electrical heating-DHW system choice; equals } 1 \text {, if system nehwj of } \\
\text { category nehwi is selected, else equals } 0\end{array}$ \\
\hline$x_{u b}^{S L C}$ & $\begin{array}{c}\text { Solar collector choice; equals } 1 \text { if system } b \text { of category } u \text { is selected, else } \\
\text { equals } 0\end{array}$ \\
\hline $\mathbf{x}$ & Vector of all decision variables $x$ \\
\hline
\end{tabular}

\section{Appendix B.2. Multi-Objective Decision Model}

Minimize

$$
\begin{gathered}
g_{1}(\mathbf{x})=\frac{Q^{H D} S E H_{e l}}{n_{e l}}+\sum_{f u e l=1}^{F U E L}\left(Q^{H D} S E H_{n e l, f u e l}\right)+\frac{Q^{C D} S E C_{e l}}{n_{e l}}+\frac{Q^{W D} S E W_{e l}}{n_{e l}}+\sum_{f u e l=1}^{F U E L}\left(Q^{W D} S E W_{\text {nel }, f u e l}\right) \\
g_{2}(\mathbf{x})=\left(Q^{H D} S E H_{e l}+Q^{C D} S E C_{e l}+Q^{W D} S E W_{e l}\right) F_{\text {station }}+\sum_{f u e l=1}^{F U E L}\left(Q^{H D} S E H_{n e l, f u e l}+Q^{W D} S E W_{\text {nel }, f u e l}\right) \frac{F_{f u e l}}{L H P_{f u e l}} \\
g_{3}(\mathbf{x})=\operatorname{COST}_{D O R}+\operatorname{COST}_{W I N}+\operatorname{COST}_{W A L}+\operatorname{COST}_{C E I L}+\operatorname{COST}_{F L O}+\operatorname{COST}_{H S}+\operatorname{COST}_{C S}+\operatorname{COST}_{W S} \\
+\operatorname{COST}_{H C S}+\operatorname{COST}_{H W S}+\operatorname{COST}_{S L C}
\end{gathered}
$$

Subject to

$$
\begin{aligned}
& Q^{H D}=\sum_{n=1}^{12} Q_{n}^{H D} \\
& Q^{C D}=\sum_{n=1}^{12} Q_{n}^{C D} \\
& Q^{W D}=\sum_{n=1}^{12}\left(W S_{n} D Q_{d D H W, n}\right) \\
& S E H_{\text {el }}=\sum_{\text {ehi=1 }}^{E H I} \sum_{\text {ehj }=1}^{E H J_{\text {ehi }}}\left(\frac{x_{\text {ehi,ehj }}^{E H}}{e_{\text {ehi,ehj }}^{E H}}\right)+\sum_{\text {ehci=1 }}^{E H C I} \sum_{\text {ehcj }=1}^{E H C J_{\text {ehci }}}\left(\frac{x_{\text {ehci, } \text {,hcj }}^{E H C}}{e_{\text {ehci,ehcj }}^{E H C}}\right)+\sum_{\text {ehwi }=1}^{E H W I} \sum_{\text {ehwj }=1}^{E H W J_{\text {ehwi }}}\left(\frac{x_{\text {ehwi,ehwj }}^{E H W}}{e_{\text {ehwi,ehwj }}^{E H W}}\right)
\end{aligned}
$$

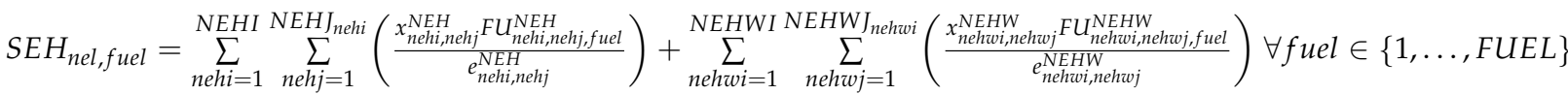




$$
\begin{gathered}
S E C_{e l}=\sum_{e c i=1}^{E C I} \sum_{e c j=1}^{E C J_{e c i}}\left(\frac{x_{e c i, e c j}^{E C}}{e_{e c i, e c j}^{E C}}\right)+\sum_{e h c i=1}^{E H C I} \sum_{e h c j=1}^{E H C J_{e h c i}}\left(\frac{x_{e h c i, e h c j}^{E H C}}{e_{e h c i, e h c j}^{E H C}}\right) \\
S E W_{e l}=\sum_{e w i=1}^{E W I} \sum_{e w j=1}^{E W J_{e w i}}\left(\frac{x_{e w i, e w j}^{E W}}{e_{e w w i, e w j}^{E W}}\right)+\sum_{e h w i=1}^{E H W I} \sum_{e h w j=1}^{E H W J_{e h w i}}\left(\frac{x_{e h w i, e h w j}^{E H W}}{e_{e h w i, e h w j}^{E H W}}\right)
\end{gathered}
$$

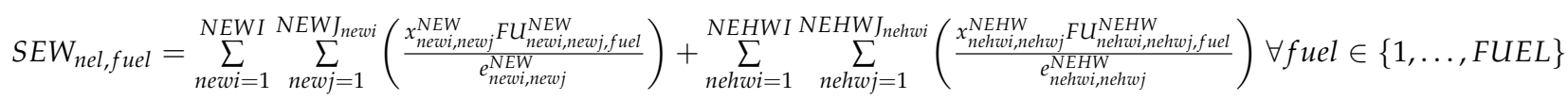

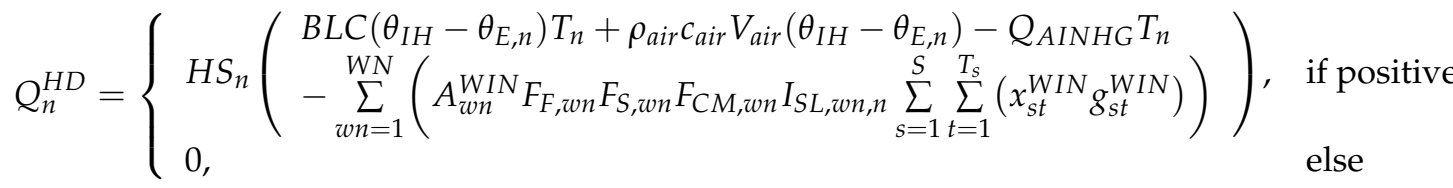

$$
\begin{aligned}
& Q_{n}^{C D}= \begin{cases}C S_{n}\left(\begin{array}{l}
\sum_{w n=1}^{W N}\left(A_{w n}^{W I N} F_{F, w n} F_{S, w n} F_{C M, w n} I_{S L, w n, n} \sum_{s=1}^{S} \sum_{t=1}^{T_{s}}\left(x_{s t}^{W I N} g_{s t}^{W I N}\right)\right) \\
+Q_{A I N H G} T_{n}-B L C\left(\theta_{I C}-\theta_{E, n}\right) T_{n}-\rho_{\text {air }} C_{a i r} V_{a i r}\left(\theta_{I C}-\theta_{E, n}\right)
\end{array}\right), & \text { if positive } \\
0, & \text { else }\end{cases} \\
& B L C=\sum_{d r=1}^{D R}\left(A_{d r}^{D O R} b_{d r}^{D O R}\right) \sum_{v=1}^{V}\left(x_{v}^{D O R} U_{v}^{D O R}\right)+\sum_{w n=1}^{W N}\left(A_{w n}^{W I N} b_{w n}^{W I N}\right) \sum_{s=1}^{S} \sum_{t=1}^{T_{s}}\left(x_{s t}^{W I N} U_{s t}^{W I N}\right) \\
& +\frac{\sum_{w l=1}^{W L}\left(A_{w l}^{W A L} b_{w l}^{W A L}\right)}{\sum_{w=1}^{W}\left(x_{w}^{W A L}\left(\sum_{k w l=1}^{K W L w}\left(\frac{d_{w w, k w l}^{d W A L}}{k k_{w, k w l}^{m W N A L}}\right)+\sum_{y=1}^{Y_{w}}\left(x_{w y}^{d W A L} \sum_{c=1}^{C_{w w y}}\left(\frac{x_{w y c}^{m W A L}}{k_{w y \mathcal{W}}^{m W A L}}\right)\right)\right)\right)} \\
& +\frac{\sum_{c e=1}^{C E}\left(A_{c e}^{C E I L} b_{c e}^{C E I L}\right)}{\sum_{d=1}^{D}\left(x_{d}^{C E I L}\left(\sum_{k c l=1}^{K C L_{d}}\left(\frac{d_{d, k E l}^{d C E I L}}{k k_{d, k c l}^{m C E I L}}\right)+\sum_{f=1}^{F_{d}}\left(x_{d f}^{d C E I L} \sum_{a=1}^{A_{d f}}\left(\frac{x_{d f a}^{m C E I L}}{k_{d f a}^{m C E I L}}\right)\right)\right)\right)} \\
& +\frac{\sum_{f l=1}^{F L}\left(A_{f l}^{F L O} b_{f l}^{F L O}\right)}{\sum_{h=1}^{H}\left(x_{h}^{F L O}\left(\sum_{k f l=1}^{K F L}\left(\frac{d_{h, k f l}^{d F L O}}{k k_{h, k f l}^{m L L O}}\right)+\sum_{e=1}^{E_{h}}\left(x_{h e}^{d F L O} \sum_{g=1}^{G h e}\left(\frac{x_{h e g}^{m F L O}}{k_{h e g}^{m F L O}}\right)\right)\right)\right)}
\end{aligned}
$$$$
D Q_{D H W, n}= \begin{cases}Q_{d h w u}-\frac{A_{S L C} I_{S L, S L C, n} F_{S, S L C} \sum_{u=1}^{U} \sum_{b=1}^{B_{u}}\left(x_{u b}^{S L C} e_{u b}^{S L C}\right)}{10^{6}}, & \text { if } Q_{d h w u} \geq \frac{A_{S L C} I_{S L, S L C, n} F_{S, S L C} \sum_{u=1}^{U} \sum_{b=1}^{B_{u}}\left(x_{u b}^{S L C} e_{u b}^{S L C}\right)}{10^{6}} \\ 0, & \text { else }\end{cases}
$$$$
Q_{d S L C, n}=\frac{A_{S L C} I_{S L, S L C, n} F_{S, S L C} \sum_{u=1}^{U} \sum_{b=1}^{B_{u}}\left(x_{u b}^{S L C} e_{u b}^{S L C}\right)}{10^{6}}
$$$$
\operatorname{COST}_{D O R}=\sum_{d r=1}^{D R}\left(A_{d r}^{D O R}\right) \sum_{v=1}^{V}\left(x_{v}^{D O R} C_{v}^{D O R}\right)
$$$$
\operatorname{COST}_{W I N}=\sum_{w n=1}^{W N}\left(A_{s t}^{W I N}\right) \sum_{s=1}^{S} \sum_{t=1}^{T_{s}}\left(x_{s t}^{W I N} C_{s t}^{W I N}\right)
$$$$
\operatorname{COST}_{W A L}=\sum_{w l=1}^{W L}\left(A_{w l}^{W A L}\right) \sum_{w=1}^{W}\left(x_{w}^{W A L}\left(\sum_{k w l=1}^{K W L_{w}}\left(d_{w, k w l}^{d W A L} C K_{w, k w l}^{m W A L}\right)+\sum_{y=1}^{Y_{w}}\left(x_{w y}^{d W A L} \sum_{c=1}^{C_{w y}}\left(x_{w y c}^{m W A L} C_{w y c}^{m W A L}\right)\right)\right)\right)
$$$$
\operatorname{COST}_{C E I L}=\sum_{c e=1}^{C E}\left(A_{c e}^{C E I L}\right) \sum_{d=1}^{D}\left(x_{d}^{C E I L}\left(\sum_{k c l=1}^{K C L_{d}}\left(d_{d, k c l}^{d C E I L} C K_{d, k c l}^{m C E I L}\right)+\sum_{f=1}^{F_{d}}\left(x_{d f}^{d C E I L} \sum_{a=1}^{A_{d f}}\left(x_{d f a}^{m C E I L} C_{d f a}^{m C E I L}\right)\right)\right)\right)
$$ 


$$
\begin{aligned}
& \operatorname{COST}_{F L O}=\sum_{f l=1}^{F L}\left(A_{f l}^{F L O}\right) \sum_{h=1}^{H}\left(x_{h}^{F L O}\left(\sum_{k f l=1}^{K F L h}\left(d_{h, k f l}^{d F L O} C K_{h, k f l}^{m F L O}\right)+\sum_{e=1}^{E_{h}}\left(x_{h e}^{d F L O} \sum_{g=1}^{G_{h e}}\left(x_{h e g}^{m F L O} C_{h e g}^{m F L O}\right)\right)\right)\right) \\
& \operatorname{COST}_{H S}=\sum_{\text {ehi=1 }}^{E H I} \sum_{\text {ehj=1 }}^{E H J_{\text {ehi }}}\left(x_{\text {ehi,ehj }}^{E H} \operatorname{CST}_{\text {ehi,ehj }}^{E H}\right)+\sum_{n e h i=1}^{N E H I} \sum_{n e h j=1}^{N E H J_{n e h i}}\left(x_{n e h i, n e h j}^{N E H} C^{N H} T_{n e h i, n e h j}^{N E H}\right) \\
& \operatorname{COST}_{C S}=\sum_{e c i=1}^{E C I} \sum_{e c j=1}^{E C J_{e c i}}\left(x_{e c i, e c j}^{E C} C S T_{e c i, e c j}^{E C}\right) \\
& \operatorname{COST}_{W S}=\sum_{e w i=1}^{E W I} \sum_{e w j=1}^{E W J_{e h i}}\left(x_{e w i, e w j}^{E W} C S T_{e w i, e w j}^{E W}\right)+\sum_{n e w i=1}^{N E W I} \sum_{n e w j=1}^{N E W J_{n e h i}}\left(x_{n e w i, n e w j}^{N E W} C S T_{n e w i, n e w j}^{N E W}\right) \\
& \operatorname{COST}_{H C S}=\sum_{\text {ehci=1 }}^{E H C I} \sum_{\text {ehcj=1 }}^{E H C J_{\text {ehci }}}\left(x_{\text {ehci,ehcj }}^{E H C} C S T_{\text {ehci,ehcj }}^{E H C}\right) \\
& \operatorname{COST}_{H W S}=\sum_{\text {ehwi=1 }}^{E H W I} \sum_{\text {ehwj=1 }}^{E H W J_{\text {ehwi }}}\left(x_{\text {ehwi,ehwj }}^{E H W} \operatorname{CST}_{\text {ehwi,ehwj }}^{E H W}\right)+\sum_{n e h w i=1}^{N E H W I} \sum_{n e h w j=1}^{N E H W J_{\text {nehwi }}}\left(x_{\text {nehwi,nehwj }}^{N E H W} \operatorname{CST}_{n e h w i, n e h w j}^{N E H W}\right) \\
& \operatorname{COST}_{S L C}=A_{S L C} \sum_{u=1}^{U} \sum_{b=1}^{B_{u}}\left(x_{u b}^{S L C} C^{S S T} T_{u b}^{S L C}\right) \\
& \sum_{v=1}^{V} x_{v}^{D O R}=1 \\
& \sum_{s=1}^{S} \sum_{t=1}^{T_{S}} x_{s t}^{W I N}=1 \\
& \sum_{w=1}^{W} x_{w}^{W A L}=1 \\
& \sum_{c=1}^{C_{w y}} x_{w y c}^{m W A L}=x_{w}^{W A L}, \forall\left(y=1, \ldots, Y_{w}, \forall w=1, \ldots, W\right) \\
& x_{w y}^{d W A L} \in\left[0, d_{\max , w y}^{W A L}\right], \forall\left(y=1, \ldots, Y_{w}, \forall w=1, \ldots, W\right) \\
& \sum_{d=1}^{D} x_{d}^{C E I L}=1 \\
& \sum_{a=1}^{A_{d f}} x_{d f a}^{m C E I L}=x_{d}^{C E I L}, \forall\left(f=1, \ldots, F_{d}, \forall d=1, \ldots, D\right) \\
& x_{d f}^{d C E I L} \in\left[0, d_{\max , d f}^{C E I L}\right], \forall\left(f=1, \ldots, F_{d}, \forall d=1, \ldots, D\right) \\
& \sum_{h=1}^{H} x_{h}^{F L O}=1 \\
& \sum_{g=1}^{G_{h e}} x_{h e g}^{m F L O}=x_{h}^{F L O}, \forall\left(e=1, \ldots, E_{h}, \forall h=1, \ldots, H\right) \\
& x_{h e}^{d F L O} \in\left[0, d_{\max , h e}^{F L O}\right], \forall\left(e=1, \ldots, E_{h}, \forall h=1, \ldots, H\right)
\end{aligned}
$$

$\sum_{\text {ehi=1 }}^{E H I} \sum_{\text {ehj } j=1}^{E H J_{\text {ehi }}} x_{\text {ehi,ehj }}^{E H}+\sum_{\text {ehci=1 }}^{E H C I} \sum_{\text {ehcj=1 }}^{E H C J_{\text {ehci }}} x_{\text {ehci,ehcj }}^{E H C}+\sum_{\text {ehwi=1 }}^{E H W I} \sum_{\text {ehwj=1 }}^{E H W J_{\text {ehwi }}} x_{\text {ehwi,ehwj }}^{E H W}+\sum_{n e h i=1}^{N E H I} \sum_{n e h j=1}^{N E H J_{\text {nehi }}} x_{\text {nehi,nehj }}^{N E H}+\sum_{n e h w i=1}^{N E H W I} \sum_{n e h w j=1}^{N E H W J_{\text {nehwi }}} x_{n e h w i, n e h w j}^{N E H W}=1$

$$
\sum_{e c i=1}^{E C I} \sum_{e c j=1}^{E C J_{e c i}} x_{e c i, e c j}^{E C}+\sum_{e h c i=1}^{E H C I} \sum_{e h c j=1}^{E H C J_{e h c i}} x_{e h c i, e h c j}^{E H C}=1
$$

$$
\begin{gathered}
\sum_{e w i=1}^{E W I} \sum_{e w j=1}^{E W J_{e h i}} x_{e w i, e w j}^{E W}+\sum_{e h w i=1}^{E H W I} \sum_{e h w j=1}^{E H W J_{e h w i}} x_{e h w i, e h w j}^{E H W}+\sum_{n e w i=1}^{N E W I} \sum_{n e w j=1}^{N E W J_{\text {newi }}} x_{n e w i, n e w j}^{N E W}+\sum_{n e h w i=1}^{N E H W I} \sum_{n e h w j=1}^{N E H W J_{n e h w i}} x_{n e h w i, n e h w j}^{N E H W}=1 \\
\sum_{u=1}^{U} \sum_{b=1}^{B_{u}} x_{u b}^{S L C} \leq 1
\end{gathered}
$$




\section{References}

1. Costa-Carrapiço, I.; Raslan, R.; González, J.N. A systematic review of genetic algorithm-based multi-objective optimisation for building retrofitting strategies towards energy efficiency. Energy Build. 2020, 210, 109690. [CrossRef]

2. Hashempour, N.; Taherkhani, R.; Mahdikhani, M. Energy performance optimization of existing buildings: A literature review. Sustain. Cities Soc. 2020, 54, 101967. [CrossRef]

3. Wulfinghoff, D.R. Energy Efficiency Manual; Energy Institute Press: Wheaton, MD, USA, 1999.

4. Diakaki, C.; Grigoroudis, E.; Kolokotsa, D. Towards a multi-objective optimization approach for improving energy efficiency in buildings. Energy Build. 2008, 40, 1747-1754. [CrossRef]

5. Diakaki, C.; Grigoroudis, E.; Kabelis, N.; Kolokotsa, D.; Kalaitzakis, K.; Stavrakakis, G. A multi-objective decision model for the improvement of energy efficiency in buildings. Energy 2010, 35, 5483-5496. [CrossRef]

6. Diakaki, C.; Grigoroudis, E. Applying genetic algorithms to optimise energy efficiency in buildings. In Multicriteria Decision Aid and Artificial Intelligence: Links, Theory and Applications; Doumpos, M., Grigoroudis, E., Eds.; John Wiley \& Sons Ltd: Hoboken, NJ, USA, 2013; pp. 309-333. [CrossRef]

7. Diakaki, C.; Grigoroudis, E.; Kolokotsa, D. Performance study of a multi-objective mathematical programming modelling approach for energy decision-making in buildings. Energy 2013, 59, 534-542. [CrossRef]

8. Ren, H.; Zhou, W.; Gao, W.; Wu, Q. A mixed-integer linear optimization model for local energy system planning based on simplex and branch-and-bound algorithms. In Life System Modeling and Intelligent Computing; Li, K., Fei, M., Jia, L., Irwin, G.W., Eds.; Springer: Berlin/Heidelberg, Germany, 2010; Volume 6328, pp. 361-371. [CrossRef]

9. Asadi, E.; Da Silva, M.G.; Antunes, C.H.; Dias, L. Multi-objective optimization for building retrofit strategies: A model and an application. Energy Build. 2012, 44, 81-87. [CrossRef]

10. Üçtug, F.G.; Yukseltan, E. A linear programming approach to household energy conservation: Efficient allocation of budget. Energy Build. 2013, 49, 200-208. [CrossRef]

11. Karmellos, M.; Kiprakis, A.; Mavrotas, G. A multi-objective approach for optimal prioritization of energy efficiency measures in buildings: Model, software and case studies. Appl. Energy 2015, 139, 131-150. [CrossRef]

12. Bayata, O.; Temiz, I. Developing a model and software for energy efficiency optimization in the building design process: A case study in Turkey. Turk. J. Electr. Eng. Comput. Sci. 2017, 25, 4172-4186. [CrossRef]

13. Shakouri, G.H.; Rahmani, M.; Hosseinzadeh, M.; Kazemi, A. Multi-objective optimization-simulation model to improve the buildings' design specification in different climate zones of Iran. Sustain. Cities Soc. 2018, 40, 394-415. [CrossRef]

14. Nielsen, A.N.; Jensen, R.L.; Larsen, T.S.; Nissen, S.B. Early stage decision support for sustainable building renovation-A review. Build. Environ. 2016, 103, 165-181. [CrossRef]

15. Siskos, J.; Despotis, D.K. A DSS oriented method for multiobjective linear programming problems. Decis. Support. Syst. 1989, 5, 47-55. [CrossRef]

16. Siskos, Y.; Yannacopoulos, D. UTASTAR: An ordinal regression method for building additive value functions. Investig. Oper. 1985, 5, 39-53.

17. Kreider, J.F.; Curtiss, P.; Rabl, A. Heating and Cooling for Buildings, Design for Efficiency; McGraw-Hill: New York, NY, USA, 2002.

18. Zopounidis, C.; Despotis, D.K.; Kamaratou, I. Portfolio selection using the ADELAIS multiobjective linear programming System. Comput. Econ. 1998, 11, 189-204. [CrossRef]

19. Lee, S.H.; Hong, T.; Piette, M.A.; Taylor-Lange, S.C. Energy retrofit analysis toolkits for commercial buildings: A review. Energy 2015, 89, 1087-1100. [CrossRef] 